\title{
Review
}

\section{Progress of electrochemical $\mathrm{CO}_{2}$ reduction reactions over polyoxometalate-based materials}

\author{
Jing Du a,†, Yuan-Yuan Ma d, $\uparrow$, Huaqiao Tan a,*, Zhen-Hui Kang b,c,\#, Yangguang Li a,\$ \\ a Key Laboratory of Polyoxometalate Science of the Ministry of Education, Faculty of Chemistry, Northeast Normal University, Changchun 130024, Jilin, \\ China \\ b Institute of Advanced Materials, Northeast Normal University, Changchun 130024, Jilin, China \\ c Institute of Functional Nano and Soft Materials (FUNSOM), Jiangsu Key Laboratory for Carbon-based Functional Materials and Devices, Soochow \\ University, Suzhou 215123, Jiangsu, China \\ d College of Chemistry and Material Science, Hebei Normal University, Shijiazhuang 050024, Hebei, China
}

\section{A R T I C L E I N F}

\section{Article history:}

Received 22 July 2020

Accepted 3 September 2020

Available online 22 November 2020

\section{Keywords:}

Polyoxometalate

Electrocatalysis

$\mathrm{CO}_{2}$ reduction

Electron transfer

Mechanism

\begin{abstract}
A B S T R A C T
Electrochemical $\mathrm{CO}_{2}$ reduction to value-added fuels and chemicals is recognized as a promising strategy to alleviate energy shortages and global warming owing to its high efficiency and economic feasibility. Recently, understanding the activity origin, selectivity regulation, and reaction mechanisms of $\mathrm{CO}_{2}$ reduction reactions $\left(\mathrm{CO}_{2} \mathrm{RRs}\right)$ has become the focus of efficient electrocatalyst design. Polyoxometalates (POMs), a unique class of nanosized metal-oxo clusters, are promising candidates for the development of efficient $\mathrm{CO}_{2} \mathrm{RR}$ electrocatalysts and, owing to their well-defined structure, remarkable electron/proton storage and transfer ability, and capacities for adsorption and activation of $\mathrm{CO}_{2}$, are ideal models for investigating the activity origin and reaction mechanisms of $\mathrm{CO}_{2} \mathrm{RR}$ electrocatalysts. In this review, we focus on the activity origin and mechanism of $\mathrm{CO}_{2} \mathrm{RRs}$ and survey recent advances that were achieved by employing POMs in electrocatalytic $\mathrm{CO}_{2} \mathrm{RRs}$. We highlight the significant roles of POMs in the electrocatalytic $\mathrm{CO}_{2} \mathrm{RR}$ process and the main factors influencing selectivity regulation and catalytic $\mathrm{CO}_{2} \mathrm{RR}$ performance, including the electrolyte, electron-transfer process, and surface characteristics. Finally, we offer a perspective of the advantages and future challenges of POM-based materials in electrocatalytic $\mathrm{CO}_{2}$ reduction that could inform new advancements in this promising research field.
\end{abstract}

(C) 2021, Dalian Institute of Chemical Physics, Chinese Academy of Sciences. Published by Elsevier B.V. All rights reserved.

\footnotetext{
* Corresponding author. E-mail: tanhq870@nenu.edu.cn

\# Corresponding author. E-mail: kangzh@nenu.edu.cn, zhkang@suda.edu.cn

\$Corresponding author. E-mail: liyg658@nenu.edu.cn

†These authors contributed equally.

This work was supported by the National Natural Science Foundation of China $(21671036,21771033,21771132,21901060,51725204,51972216$ and 52041202), the Fundamental Research Funds for the Central Universities (2412018BJ001, 2412018ZD007 and 2412018QD005), the National MCF Energy R\&D Program (2018YFE0306105), Innovative Research Group Project of the National Natural Science Foundation of China (51821002), Natural Science Foundation of Jiangsu Province (BK20190041, BK20190828), Key-Area Research and Development Program of Guangdong Province (2019B010933001), the Collaborative Innovation Center of Suzhou Nano Science \& Technology, the Priority Academic Program Development of Jiangsu Higher Education Institutions (PAPD), the 111 Project, the Scientific Development Project of Jilin Province (20190201206JC), the Foundation of Jilin Educational Committee (JJKH20190268KJ), the Specialized Research Fund for the Doctoral Program of Higher Education (20123201110018) and the Opening Project of Key Laboratory of Polyoxometalate Science of Ministry of Education.

DOI: 10.1016/S1872-2067(20)63718-4 | http://www.sciencedirect.com/science/journal/18722067 | Chin. J. Catal., Vol. 42 , No. 6, June 2021
} 


\section{Introduction}

With the continuous growth of the global population and industrial development, the demand for fossil fuels increases daily, exacerbating the energy shortage while the significant carbon dioxide $\left(\mathrm{CO}_{2}\right)$ emissions accompanying the use of fossil fuels adversely affects the global environment [1]. The concentration of $\mathrm{CO}_{2}$ in the atmosphere has risen from $0.028 \%$ before the industrial revolution to over $0.041 \%$ in 2020 and continues to increase at a rate of $2.1 \times 10^{-6}$ per year [2,3]. Such high concentrations of $\mathrm{CO}_{2}$ cause a series of environmental problems such as global warming [4], increased desertification [5], seawater acidification [6], and the extinction of species [7]. Conversely, the $\mathrm{CO}_{2}$ in the atmosphere is an indispensable $\mathrm{C} 1$ resource for plant growth and various industrial process. Thus, the reasonable utilization and conversion of $\mathrm{CO}_{2}$ into high value-added chemicals presents a promising, clean, and carbon-neutral strategy to alleviate $\mathrm{CO}_{2}$-induced environmental problems and meet future energy demands.

Structurally, a $\mathrm{CO}_{2}$ molecule is linear and centrosymmetric, which endows it with exceptional stability, intrinsic chemical inertia, low electron affinity, and a large energy gap (13.7 eV) [8]. These features make the transformation of $\mathrm{CO}_{2}$ a challenging process that requires a substantial input of energy that can only proceed under harsh reaction conditions. Moreover, the practical application of $\mathrm{CO}_{2}$ conversion and concomitant product utilization are hampered by the high energy requirements of $\mathrm{CO}_{2}$ conversion, insufficient socio-economic motivation, and a lack of industry commitment to promote $\mathrm{CO}_{2}$-related chemicals [9-11]. Despite the status quo, diverse routes to convert $\mathrm{CO}_{2}$ into carbon-based chemicals and fuels have been developed, which include chemical reforming [12], mineralization [13], biochemical [14], photochemical [15], thermochemical [16], and electrochemical reactions [17-20]. Among these approaches, the photochemical or electrochemical $\mathrm{CO}_{2}$ reduction technologies, driven by clean and renewable energy, have attracted enormous attention and display huge potential for future industrial applications owing to their environmental compatibility and operation under ambient temperature and pressure. In particular, electrocatalytic $\mathrm{CO}_{2}$ reduction reactions $\left(\mathrm{CO}_{2} \mathrm{RRs}\right)$ present a promising alternative approach offering various advantages, including controllable applied voltages and reaction temperatures, recyclable supporting electrolytes, sustainable input energy sources, and easy to scale up application [21-23]. However, researchers in the field of electrocatalytic reduction of $\mathrm{CO}_{2}$ still face the challenges of large overpotentials, slow electron transfer kinetics, unsatisfactory selectivity, and low energy efficiency due to accompanying solvent decomposition reactions [24-26]. Electrocatalysts have been recognized as the key to improving $\mathrm{CO}_{2}$ electroreduction performance.

In the electroreduction process of $\mathrm{CO}_{2}$, the $\mathrm{C}=\mathrm{O}$ bonds are broken by high-energy electrons and protons to selectively produce small carbonaceous molecules with high energy densities, such as formic acid ( $\mathrm{HCOOH}, 2 \mathrm{e} / 2 \mathrm{H}$ reduction), carbon monoxide (CO, $2 \mathrm{e} / 2 \mathrm{H}$ reduction), and methanol $\left(\mathrm{CH}_{3} \mathrm{OH}, 6 \mathrm{e} / 6 \mathrm{H}\right.$ reduction), methane $\left(\mathrm{CH}_{4}, 8 \mathrm{e} / 8 \mathrm{H}\right.$ reduction), or some $\mathrm{C} 2$ products such as ethylene $\left(\mathrm{C}_{2} \mathrm{H}_{4}\right)$, ethane $\left(\mathrm{C}_{2} \mathrm{H}_{6}\right)$, and ethanol
$\left(\mathrm{CH}_{3} \mathrm{CH}_{2} \mathrm{OH}\right)$ via $\mathrm{C}-\mathrm{C}$ coupling [23]. However, the desired selectivity and optimum purity of target products depend on the selection of $\mathrm{CO}_{2} \mathrm{RR}$ electrocatalysts. Accordingly, various electrocatalysts have been developed, such as molecular electrocatalysts (e.g., metal carbonyl [25-29], macrocyclic [30-33], covalent organic framework [34-36], and metal-organic framework [37-39]), single-atom catalysts [40-42], metal[43-45] and metal alloy- [46-48], oxide- [49-50], sulfide- [51], and carbon-based materials $[52,53]$. Despite the realization of electrocatalysts with high $\mathrm{CO}_{2} \mathrm{RR}$ activity and selectivity, in-depth studies of the activity origin and selectivity regulation of electrocatalysts along with their reaction mechanisms and $\mathrm{CO}_{2} \mathrm{RR}$ processes are still required.

Polyoxometalates (POMs), an extraordinary class of nanoscale metal-oxo clusters constructed with $d^{0}$ or $d^{1}$ metal ions $(\mathrm{M}=\mathrm{W}, \mathrm{Mo}, \mathrm{Nb}, \mathrm{V}$, etc.) bridged via shared oxygen atoms, have attracted attention in various fields, such as catalysis [54-56], medicine [57], material [58] and energy [59], owing to their well-defined structures and fascinating physical and chemical properties. The application of POMs in electrocatalytic $\mathrm{CO}_{2} \mathrm{RRs}$ is growing rapidly. In 2002, Kozik et al. [60] reported the first investigation into electrocatalytic $\mathrm{CO}_{2}$ reduction using a homogeneous transition metal (TM)-substituted POM catalyst. Recent years have seen a rapid increase in the number reports featuring POM-based $\mathrm{CO}_{2} \mathrm{RR}$ electrocatalysts, which mainly concern the well-defined adjustable structure, unique electrochemical redox properties, and flexible modifiability of POMs. The adjustable structure and composition of POMs can accommodate more than one kind of TM atom allowing the precision construction of TM-substituted POMs with metalloporphyrin-like properties, which are ideal models for understanding the interaction between metal atoms and ligands in molecular catalysis. Moreover, POMs, as a class of uniformly nanosized metal-oxo clusters, possess the characteristics of both molecules and nanoclusters, and also display surface features similar to TM oxides [61] and sulfides [62,63], offering an important platform for the in-depth investigation of nano-catalyst surface chemistry and adsorption processes. Furthermore,

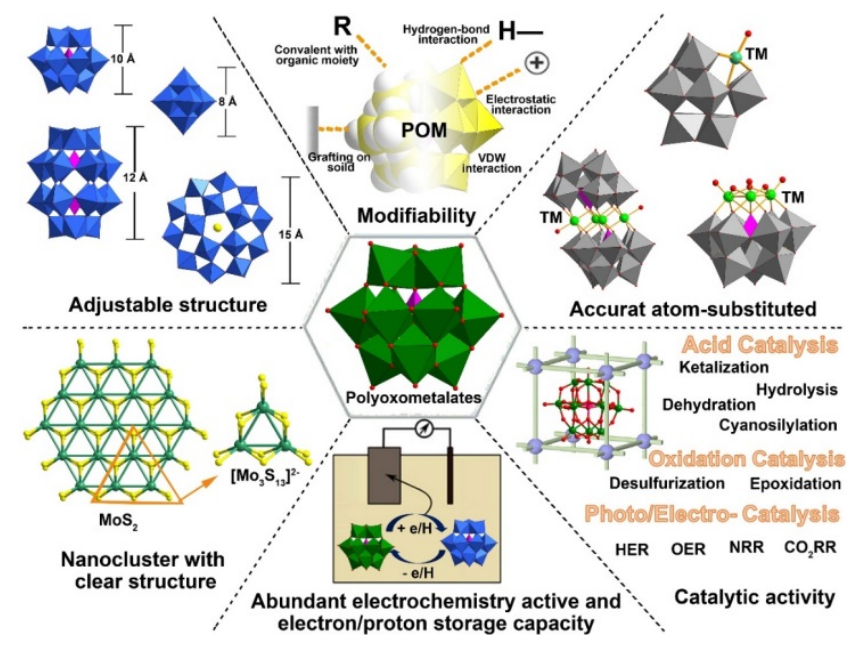

Scheme 1. The various features of POMs including an adjustable structure, modifiability, electrochemical redox properties, and catalytic activity. 
POMs can serve as flexible scaffolds that can be assembled via organic modification [64], electrostatic/hydrogen bonding interaction, or host-guest interactions to form POM-based composite materials [65]. In these POM-based composite materials, POMs can undergo reversible multivalent reductions/oxidations to form mixed-valence species while retaining their structural integrity. The outstanding electron/proton storage and transport capacities of POMs also provide a convenient model for studying the redox reactions and electron/proton coupling transfer behaviors of multicomponent catalysts in the electrochemical process [66]. Therefore, POMs play an indispensable and irreplaceable role in multiscale electrocatalysis (Scheme 1). They can bridge molecular- (homogeneous catalysis) and nano-electrocatalysts (heterogeneous catalysis), to offer an ideal catalyst model for the in-depth understanding of $\mathrm{CO}_{2} \mathrm{RR}$ mechanisms and the structure-activity relationships in complicated electrocatalyst systems.

In the past few years, POMs have been widely used in the field of $\mathrm{CO}_{2}$ conversion and chemical fixation, and several impressive reviews have been published that mainly focus on thermal and photocatalytic $\mathrm{CO}_{2}$ conversion. He et al. [67] and $\mathrm{Hu}$ et al. [68] reviewed the use of $\mathrm{POMs}$ in $\mathrm{CO}_{2}$ cycloaddition reactions and speculated on the adsorption process and reaction mechanism of $\mathrm{CO}_{2}$ on POM surfaces. With the rapid development of POMs in electrocatalysis, several reviews on POM-based electrocatalysts have also been published. He and co-workers [69] summarized the application of POMs in $\mathrm{CO}_{2}$-involved photo/electrocatalysis and carbonylation, while Lan et al. [70] discussed the application of POM-based materials in various energy-related reactions, some of which involved POM-based $\mathrm{CO}_{2} \mathrm{RR}$ electrocatalysts. The limited review papers available on electrocatalytic $\mathrm{CO}_{2}$ RRs over POMs mainly summarize catalyst types and catalytic performance. Whereas, a systematic and comprehensive review on the application of POMs in electrocatalytic $\mathrm{CO}_{2} \mathrm{RRs}$ is not available. The urgent need for a deeper understanding of the activity origin, selectivity regulation, and reaction mechanism of $\mathrm{CO}_{2} \mathrm{RRs}$ over POMs prompted us to systematically review the latest progress in POM-involved electrocatalytic $\mathrm{CO}_{2}$ reduction.

In this review, we focus on the mechanisms and the major advances involving POMs and electrocatalytic $\mathrm{CO}_{2} \mathrm{RRs}$, and highlight the significant roles of POMs in such electrocatalytic processes. Particular attention is paid to the catalytic activity origin of electrocatalytic $\mathrm{CO}_{2} \mathrm{RRs}$ over POMs, the main principles of selectivity regulation and factors influencing catalytic $\mathrm{CO}_{2} \mathrm{RR}$ performance, including the electrolyte, electron transfer process, and surface characteristics. Finally, we briefly discuss the challenges and perspectives of electrocatalytic $\mathrm{CO}_{2}$ reduction over POM-based materials, and speculate on possible future directions for the development of efficient and controllable $\mathrm{CO}_{2} \mathrm{RR}$ electrocatalysts.

\section{Fundamental understanding of electrocatalytic $\mathrm{CO}_{2}$ reduction reactions}

Understanding the mechanisms of $\mathrm{CO}_{2} \mathrm{RRs}$ is crucial to improving product selectivity and efficiency. $\mathrm{CO}_{2}$ molecules have
Table 1

Electrochemical potentials of reactions that may occur during electrocatalytic $\mathrm{CO}_{2}$ reduction in aqueous solutions.

\begin{tabular}{lc}
\hline Possible half-reactions in electrochemical $\mathrm{CO}_{2}$ RRs & $\begin{array}{c}\text { Electrode potentials } \\
\text { (V vs. SHE) }\end{array}$ \\
\hline $\mathrm{CO}_{2}(\mathrm{~g})+\mathrm{e}^{-} \rightarrow{ }^{*} \mathrm{COO}^{-}$ & -1.90 \\
$\mathrm{CO}_{2}(\mathrm{~g})+2 \mathrm{H}^{+}+2 \mathrm{e}^{-} \rightarrow \mathrm{CO}(\mathrm{g})+\mathrm{H}_{2} \mathrm{O}(\mathrm{l})$ & -0.52 \\
$\mathrm{CO}_{2}(\mathrm{~g})+8 \mathrm{H}^{+}+8 \mathrm{e}^{-} \rightarrow \mathrm{CH}_{4}(\mathrm{~g})+2 \mathrm{H}_{2} \mathrm{O}(\mathrm{l})$ & -0.24 \\
$2 \mathrm{CO}_{2}(\mathrm{~g})+12 \mathrm{H}^{+}+12 \mathrm{e}^{-} \rightarrow \mathrm{C}_{2} \mathrm{H}_{4}(\mathrm{~g})+4 \mathrm{H}_{2} \mathrm{O}(\mathrm{l})$ & -0.34 \\
$\mathrm{CO}_{2}(\mathrm{~g})+2 \mathrm{H}^{+}+2 \mathrm{e}^{-} \rightarrow \mathrm{HCOOH}(\mathrm{l})$ & -0.61 \\
$\mathrm{CO}_{2}(\mathrm{~g})+4 \mathrm{H}^{+}+4 \mathrm{e}^{-} \rightarrow \mathrm{HCHO}(\mathrm{l})+\mathrm{H}_{2} \mathrm{O}(\mathrm{l})$ & -0.51 \\
$\mathrm{CO}_{2}(\mathrm{~g})+6 \mathrm{H}^{+}(\mathrm{l})+6 \mathrm{e}^{-} \rightarrow \mathrm{CH}_{3} \mathrm{OH}(\mathrm{l})+\mathrm{H}_{2} \mathrm{O}(\mathrm{l})$ & -0.38 \\
$2 \mathrm{H}^{+}+2 \mathrm{e}^{-} \rightarrow \mathrm{H}_{2}(\mathrm{~g})$ & -0.42 \\
\hline
\end{tabular}

two vertical conjugated $\pi$ bonds, which induce a high bond energy, high chemical stability, and chemical inertia [71]. It is, therefore, necessary to design and develop highly efficient electrocatalysts to promote electrocatalytic $\mathrm{CO}_{2} \mathrm{RRs}$. Since the first report of metal electrode-driven electrocatalytic $\mathrm{CO}_{2}$ reduction in the 1980s, a large number of electrocatalysts have been developed [45]. However, the limited activity and product selectivity of electrocatalysts are still key weaknesses that hinder their practical application. The investigation into the electrochemical pathway of $\mathrm{CO}_{2} \mathrm{RRs}$ reported by Hori and co-workers [72] proposed that $\mathrm{CO}_{2}$ in an aqueous electrolyte is initially adsorbed on the electrode surface to form a $\mathrm{CO}_{2}{ }^{-}$radical, which is an important intermediate for the subsequent product selectivity of the $\mathrm{CO}_{2} \mathrm{RR}$ [71]. This step requires a significant amount energy ( $-1.9 \mathrm{~V} v$ s. SHE) to rearrange the linear $\mathrm{CO}_{2}$ molecule into a curved free radical anion (however, the role and reaction pathway of the intermediate in this step are still controversial) [72,73], which is the main reason for low $\mathrm{CO}_{2} \mathrm{RR}$ activity. Thus, a clear active center that easily activates $\mathrm{CO}_{2}$ molecules is the primary feature required of $\mathrm{CO}_{2} \mathrm{RR}$ electrocatalysts.

Once the $\mathrm{CO}_{2} \cdot$ - intermediate is formed in the $\mathrm{CO}_{2} \mathrm{RR}$ process, a series of proton-coupled electron transfer processes can occur efficiently. However, due to the small potential differences between the possible products (Table 1), product selectivity is

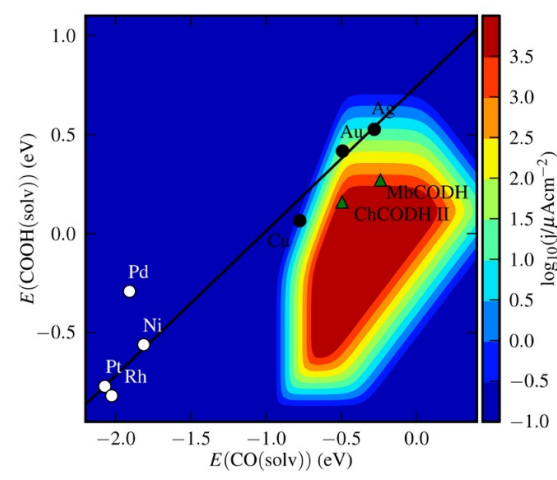

Fig. 1. Kinetic volcano plot for $\mathrm{CO}$ evolution at a $0.35 \mathrm{~V}$ overpotential from the (211) step of TMs. The TMs fall along a trendline that does not pass over the top of the volcano. However, the noble metals occupy near-optimum positions along this trend line. The specific CO evolution current for the ChCODH II and MbCODH enzyme models is comparable or better than those of the noble metals. Reprinted with the permission of Ref. [75]. Copyright 2013, American Chemical Society. 
challenging in electrocatalytic $\mathrm{CO}_{2} \mathrm{RRs}$ and usually depends largely on the adsorption characteristics of the catalyst surfaces or active sites. When the oxygen atom of the ${ }^{*} \mathrm{COO}^{-}$intermediate is protonated to form a ${ }^{*} \mathrm{COOH}$ intermediate, the $\mathrm{CO}_{2}$ reduction product tends to be $\mathrm{CO}$, whereas when the nucleophilic carbon atom in the $\mathrm{CO}_{2}{ }^{-}$intermediate is protonated to form the $\mathrm{HCOO}^{*}$ intermediate, the catalytic product is mainly formic acid [74]. Key to the regulation of $\mathrm{CO}_{2} \mathrm{RR}$ product selectivity is the optimization of intermediate adsorption energy on the surface of electrocatalysts. Nǿrskov and co-workers [75] established a kinetic volcano diagram of the adsorption energies of two intermediates $\left(\Delta E_{\mathrm{COOH}}\right.$ and $\Delta E_{\mathrm{CO}}$ ) by using density functional theory (DFT) to describe the catalytic activity trend of $\mathrm{CO}_{2}$ reduction to $\mathrm{CO}$ (Fig. 1), and found that the ideal electrocatalyst for $\mathrm{CO}_{2}$ reduction to $\mathrm{CO}$ should demonstrate suitable binding energy toward the key intermediates, ${ }^{*} \mathrm{COOH}$ and ${ }^{*} \mathrm{CO}$. As illustrated in Fig. 1, the surfaces of metals (Au and Ag) have weak binding energies toward * $\mathrm{CO}$ but strong binding energies toward ${ }^{*} \mathrm{COOH}$, limiting the activation of $\mathrm{CO}_{2}$. In the cases of $\mathrm{Pd}$, $\mathrm{Ni}, \mathrm{Pt}$, and $\mathrm{Ru}, \mathrm{CO}_{2}$ activation and conversion to adsorbed $\mathrm{CO}$ is facile but the strong binding of * $\mathrm{CO}$ limits the desorption of $\mathrm{CO}$. Moreover, the adsorption energies of different intermediates on a single TM surface are linearly correlated, that is, it is impossible to simultaneously enhance ${ }^{*} \mathrm{COOH}$ binding and decrease ${ }^{*} \mathrm{CO}$ binding at a single active site. A number of strategies have been developed to overcome the linear relationship between the binding energies of key intermediates, such as ${ }^{*} \mathrm{COOH}$ and ${ }^{*} \mathrm{CO}$. For example, adjusting the composition of alloy catalysts [17], the modification of ligands [76,77], the application of an electric field [78-80], surface engineering [81], and electron/proton transfer processes [82] can selectively stabilize the adsorbed intermediates. A doping strategy can also optimize the adsorption energies of intermediates, for example, increasing the content of subsurface oxygen in copper oxide enhances the binding of * $\mathrm{CO}$ [83]. In addition, DFT calculations predict that $\mathrm{MoS}_{2}$ and $\mathrm{MoSe}_{2}$ can break the linear relationship between the binding energies of $* \mathrm{CO},{ }^{*} \mathrm{COOH}$, and ${ }^{*} \mathrm{CHO}$ [84]. Besides the above thermodynamic characteristics, a series of kinetic characteristics, including the concentration of the electrolyte [85], the gas diffusion [86], and the presence of active sites on the catalyst surface [87], also affect the activity and selectivity of $\mathrm{CO}_{2} \mathrm{RRs}$.

Therefore, ideal $\mathrm{CO}_{2} \mathrm{RR}$ electrocatalysts should have clear active centers that can easily adsorb and activate $\mathrm{CO}_{2}$ molecules, and suitable binding energies toward specific intermediates. Moreover, considering the complicated multi-proton/ electron-coupled process involved in $\mathrm{CO}_{2} \mathrm{RRs}$, a distinct proton/electron transfer pathway is useful in understanding the selectivity regulation of electrocatalytic $\mathrm{CO}_{2} \mathrm{RRs}$. The high dispersion of catalytically active centers and appropriate electrolyte solutions are also important factors in promoting the high activity and selectivity of electrocatalytic $\mathrm{CO}_{2} \mathrm{RRs}$.

\section{Advantages of polyoxometalates in electrocatalytic $\mathrm{CO}_{2} \mathrm{RRs}$}

POMs with their unique electrochemical redox properties and outstanding electron/proton storage and transport capacities, display enormous potential as electrocatalysts. Since the first POM was reported by Berzelius in 1826, numerous POM structures have been revealed that promote the development of POM chemistry in energy-related fields [70]. In recent years, the application of POMs in electrocatalytic $\mathrm{CO}_{2} \mathrm{RRs}$ has grown rapidly, and is closely related to the POM properties. The oxygen-enriched surfaces of POMs offer Lewis base sites, endowing POMs with the ability to couple and activate $\mathrm{CO}_{2}$ molecules. In 1998, Kozik et al. [88] reported the interaction between $\mathrm{CO}_{2}$ and nonreduced heteropolyanions $\left[\alpha-\mathrm{SiW}_{11} \mathrm{O}_{39} \mathrm{Co}\left({ }_{-}\right)\right]^{6^{-}}$in a nonpolar solvent, and demonstrated the $\eta^{1}$ metal-carbon bond and hydro-bonding interaction in $\mathrm{CO}_{2}$-POM adducts through a series of spectral characterizations. Ten years later, $\mathrm{Xu}$ et al. [89] demonstrated the successful covalent bonding of $\mathrm{CO}_{2}$ molecules with polyoxoanions by slightly bending the $\mathrm{O}-\mathrm{C}-\mathrm{O}$ angles from $180^{\circ}$ to ca. $158.7^{\circ}$, to realize the fixation and activation of $\mathrm{CO}_{2}$. It should be noted that POMs can adopt various clear coordination modes to combine and activate $\mathrm{CO}_{2}$ molecules, which makes POMs the most structurally functional model for studying different adsorption and activation modes of $\mathrm{CO}_{2}$.

Moreover, POMs possess the features of both molecules and highly dispersed nanoclusters, in which the size of nanoclusters can be adjusted from 1 to $100 \mathrm{~nm}$ [90]. The surfaces of POMs are also ideal models for understanding the surfaces of nanosized metal oxides, sulfides, and nitrides. Since Caughlan et al. [91] determined the molecular structure of titanyl clusters in 1967, titanium-oxo clusters have become the most effective molecular model of the properties of nanosized $\mathrm{TiO}_{2}$, and have turned into a unique bridge between theoretical modeling, crystallography, and spectroscopy [61]. Subsequently, Wright and co-workers [92] prepared a series of cobalt (II) doped titanium oxide clusters, which were used as regulation models to study the effect of metal doping on the band gap of $\mathrm{TiO}_{2}$. Owing to the development of POM chemistry over the past two hundred years, besides the titanium-oxo clusters, the constituent elements of POMs are becoming more and more abundant. Some novel palladium-oxo clusters [93] and molybdenum sulfur clusters [63] have been discovered. These POMs provide the most accurate molecular models for understanding the effect of $\mathrm{O}$ - and S-doping on the adsorption process of key intermediates during electrocatalytic $\mathrm{CO}_{2}$ RRs. Therefore, POMs provide a molecular-scale perspective for understanding the electrocatalytic $\mathrm{CO}_{2} \mathrm{RR}$ process and are expected to present accurate models for understanding and regulating the activity and selectivity of $\mathrm{CO}_{2} \mathrm{RRs}$.

The TM atoms in POMs typically have $d^{0}$ or $d^{1}$ electronic configurations, implying that POMs have electron/proton storage and transport capacities and can undergo reversible multivalent reductions/oxidations to form mixed-valence species while retaining their structural integrity [94]. The reduced POMs generally demonstrate good solubility and solvent compatibility, and in an electron/proton buffer solution can reveal the effect of the redox behavior of the electrolyte on mass transfer and electron transfer during electrocatalytic $\mathrm{CO}_{2} \mathrm{RRs}$ [95]. The stored electrons or protons in reduced POMs can 


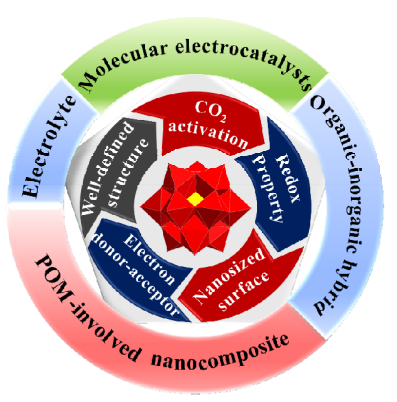

Scheme 2. The fascinating properties of POMs informing the potential application of POM-based materials in electrochemical $\mathrm{CO}_{2}$ reduction reactions.

specifically transfer to the reaction substrate through direct electron transfer or proton-coupled electron transfer mechanisms [96], which is expected to optimize the proton-coupled electron transfer process in electrocatalytic $\mathrm{CO}_{2} \mathrm{RRs}$, and regulate the selectivity of $\mathrm{CO}_{2} \mathrm{RRs}$.

In summary, POMs possess well-defined structures and the capacities for the adsorption and activation of $\mathrm{CO}_{2}$, satisfying the requirements for electrocatalytic $\mathrm{CO}_{2} \mathrm{RR}$ catalysts. Moreover, POMs can serve as a functional platform to understand key steps of the electrocatalytic $\mathrm{CO}_{2} \mathrm{RR}$ process on a molecular scale, but also as a mechanism model for understanding the effect of the properties of TM oxides and sulfides on $\mathrm{CO}_{2} \mathrm{RRs}$ (Scheme 2). Therefore, investigating the electrocatalytic $\mathrm{CO}_{2} \mathrm{RRs}$ over POMs can provide an in-depth understanding of the structure-activity relationship during electrocatalytic $\mathrm{CO}_{2} \mathrm{RRs}$ and lay the foundation for the design of efficient $\mathrm{CO}_{2} \mathrm{RR}$ electrocatalysts with high selectivity and designability for practical application.

\section{Research progress of electrocatalytic $\mathrm{CO}_{2} \mathrm{RRs}$ over POMs}

\subsection{POM-based molecular electrocatalysts for $\mathrm{CO}_{2} \mathrm{RRS}$}

POMs are considered promising homogeneous molecular catalysts for electrocatalytic $\mathrm{CO}_{2} \mathrm{RRs}$ due to their well-defined structures, and good solubility and stability in aqueous or non-polar solvents. Polyoxoanions can undergo one or more electron(s)/proton(s) coupled redox processes in solution, and their redox activities can be regulated by introducing suitable TM cations or small organic molecules. In the 1990s, there were a series of studies on TM-substituted polyoxoanions for the activation of $\mathrm{CO}_{2}$ molecules [88]. Kozik et al. [88] systematically studied the interaction of $\mathrm{CO}_{2}$ and TM-substituted POMs in nonpolar solvents and used spectroscopic evidence to prove the formation of a POM- $\mathrm{CO}_{2}$ complex. As shown in Fig. 2, a series of UV-Vis absorption, infrared (IR), and ${ }^{13} \mathrm{C}$ NMR spectra were used to prove the coordination of POMs and $\mathrm{CO}_{2}$ molecules in nonpolar solutions. The coordination mode of TM-substituted POMs is easy to observe based on the color changes of the solution. When the $\alpha$ - $\left[\mathrm{SiW}_{11} \mathrm{O}_{39} \mathrm{Co}\left(\mathrm{OH}_{2}\right)\right]^{6-}$ $\left(\mathrm{SiW}_{11} \mathrm{Co}\left(\mathrm{H}_{2} \mathrm{O}\right)\right)$ is coordinated with water, the solution appears orange-red (Fig. 1(a), Curve I), the "dry" $\mathrm{SiW}_{11} \mathrm{Co}_{-}$) appears green (Fig. 1(a), Curve II), and the $\mathrm{CO}_{2}$ coordinated $\mathrm{SiW}_{11} \mathrm{Co}\left(\mathrm{CO}_{2}\right)$ is burgundy red (Fig. 1(a), Curve II). At the same time, the IR spectrum (Figs. 1(b)-(c)) indicates two vibrations at 1675 and $1350 \mathrm{~cm}^{-1}$, which are assigned to the interactions between $\mathrm{POMs}$ and $\mathrm{CO}_{2}$. The ${ }^{13} \mathrm{C}$ NMR spectra was also used to

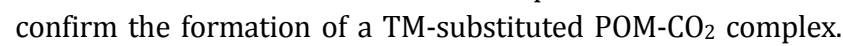
As shown as Fig. 2(d), two clear signals are attributed to the carbon atoms in a paramagnetic environment, and the complex
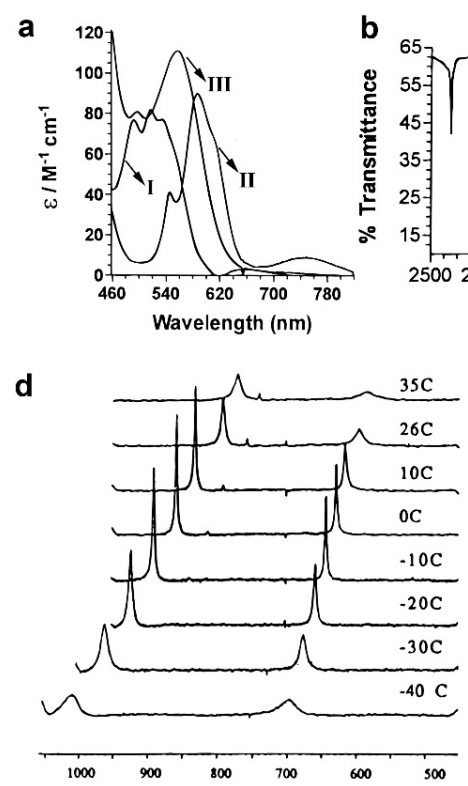
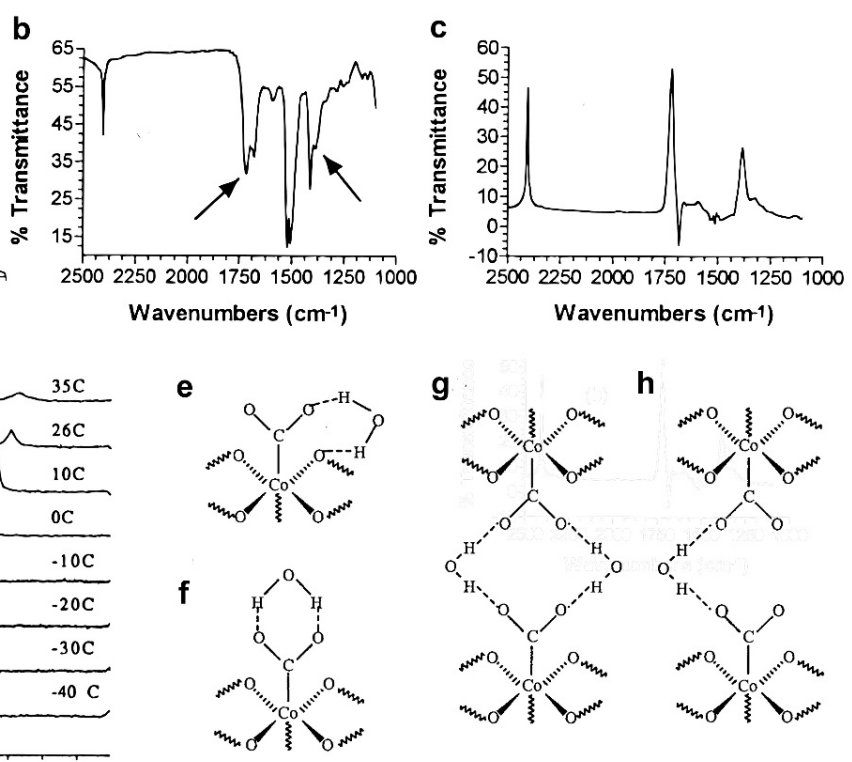

g

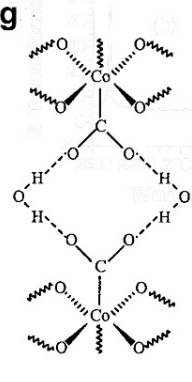

h

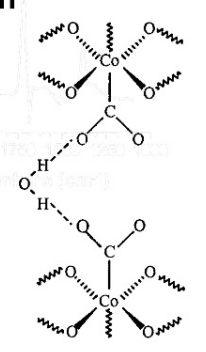

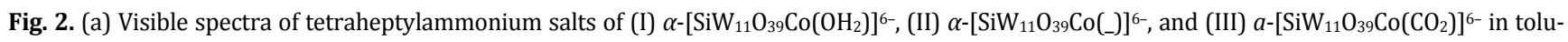
ene. (b) Infrared spectrum of the tetraheptylammonium salt of $\alpha$ - $\left[\mathrm{SiW}_{11} \mathrm{O}_{39} \mathrm{Co}\left(\mathrm{CO}_{2}\right)\right]^{6-}$ in $\mathrm{CCl}_{4}$. The two peaks marked with arrows appear after the $\mathrm{CO}_{2}$ is bubbled, and are assigned to vibrations of $\mathrm{CO}_{2}$ complexed to cobalt. (c) Difference spectrum between $\alpha$-[ $\left.\mathrm{SiW}_{11} \mathrm{O}_{39} \mathrm{Co}\left(\mathrm{CO}_{2}\right)\right]^{6-}$ and $\alpha$-[ $\left.\mathrm{SiW}_{11} \mathrm{O}_{39} \mathrm{Co}(-)\right]^{6}$. The peak at $2335 \mathrm{~cm}^{-1}$ originates from the $\mathrm{CO}_{2}$ gas dissolved in the solvent. (d) ${ }^{13} \mathrm{C}$ NMR spectra of $0.1 \mathrm{M} \alpha$ - $\left[\mathrm{SiW}_{11} \mathrm{O}_{39} \mathrm{Co}\left(\mathrm{CO}_{2}\right)\right]^{6-}$ in toluene at temperatures from $-40{ }^{\circ} \mathrm{C}$ to $+35{ }^{\circ} \mathrm{C}$. (e-h) Proposed hypothetical bonding modes for $\mathrm{CO}_{2}$ with cobalt in $\alpha$ - $\left[\mathrm{SiW}_{11} \mathrm{O}_{39} \mathrm{Co}\left(\mathrm{CO}_{2}\right)\right]^{6-}$, stabilized by hydrogen bonding utilizing both hydrogen atoms from water. Reprinted with the permission of Ref. [88]. Copyright 1998, American Chemical Society (ACS). 
is stable up to $35{ }^{\circ} \mathrm{C}$. Based on the spectroscopic characterization, the structures of four possible, water-molecule stabilized, POM-CO 2 complexes have been deduced (Figs. 2(e)-(h)). This work demonstrated for the first time the formation of complexes between TM-substituted POMs and $\mathrm{CO}_{2}$ molecules in nonpolar solutions, which provided a basis for understanding the activation of $\mathrm{CO}_{2}$ molecules and for future electrocatalytic $\mathrm{CO}_{2}$ reduction research involving POMs.

Based on this work, Kozik et al. [60] continued to study the

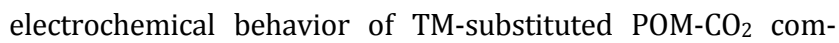
plexes and reported the first TM Co-substituted polyoxoanions $\alpha-\left[\mathrm{SiW}_{11} \mathrm{O}_{39} \mathrm{Co}\right]^{6-}\left(\mathrm{SiW}_{11} \mathrm{Co}\right)$ for electrocatalytic $\mathrm{CO}_{2} \mathrm{RRs}$ in nonpolar solvents. Compared to the cyclic voltammetry (CV) curve of $\mathrm{SiW}_{11} \mathrm{Co}$ in a dichloromethane $\left(\mathrm{CH}_{2} \mathrm{Cl}_{2}\right)$ electrolyte without $\mathrm{CO}_{2}$, the $\mathrm{CV}$ curve of $\mathrm{SiW}_{11} \mathrm{Co}$ in a $\mathrm{CH}_{2} \mathrm{Cl}_{2}$ electrolyte bubbled with $\mathrm{CO}_{2}$ achieved a higher reduction current signal, which indicated that $\mathrm{SiW}_{11} \mathrm{Co}$ has electrocatalytic $\mathrm{CO}_{2} \mathrm{RR}$ activity. For polyoxoanions $\alpha-\left[\mathrm{P}_{2} \mathrm{~W}_{18} \mathrm{O}_{62}\right]^{6-}\left(\mathrm{P}_{2} \mathrm{~W}_{18}\right)$ without TM substitution, the cyclic voltammetry curve in the $\mathrm{CH}_{2} \mathrm{Cl}_{2}$ electrolyte before and after $\mathrm{CO}_{2}$ bubbling did not change significantly, suggesting the important role of TM substituted polyoxoanions in electrocatalytic $\mathrm{CO}_{2} \mathrm{RR}$ activity. However, the $\mathrm{CV}$ curve of the $\mathrm{CO}_{2}$ reduction by $\mathrm{SiW}{ }_{11} \mathrm{Co}$ in $\mathrm{CH}_{2} \mathrm{Cl}_{2}$ showed an irreversible redox current peak, which may have been caused by the lack of protons in the electrolyte, indicating that $\mathrm{SiW}_{11}$ Co cannot stably support electrocatalytic $\mathrm{CO}_{2}$ RRs. In the presence of a proton source (such as $\mathrm{H}_{2} \mathrm{O}$ ), the vacant Co sites of $\mathrm{SiW}_{11} \mathrm{Co}$ will coordinate with water molecules and lose catalytic $\mathrm{CO}_{2} \mathrm{RR}$ activity. If $\mathrm{SiW}_{11} \mathrm{Co}$ is first reduced in an aqueous electrolyte and then transferred to toluene via tetraheptylammonium bromide (THABr), electrons and protons can be stored in SiW ${ }_{11}$ Co while preventing $\mathrm{H}_{2} \mathrm{O}$ molecules from occupying the active Co sites of $\mathrm{SiW}_{11} \mathrm{Co}$, to achieve stable electrocatalytic $\mathrm{CO}_{2} \mathrm{RRs}$ driven by $\mathrm{SiW}_{11} \mathrm{Co}_{0}$ in toluene. This work was the first to use TM-substituted polyoxoanions for electrocatalytic $\mathrm{CO}_{2} \mathrm{RRs}$, the electron/proton storage characteristics of the reduced POMs made it possible to achieve stable electrocatalytic $\mathrm{CO}_{2} \mathrm{RRs}$ with the active Co sites of polyoxoanions in a nonpolar electrolyte. This work studied the effect of the electrolyte on the activity of metal-substituted polyoxoanions in terms of electron/proton transfer and coordination chemistry, providing some insights for understanding and illustrating the working conditions of metal-complexed molecular electrocatalysts in $\mathrm{CO}_{2} \mathrm{RRs}$. However, the nature of the products or the electrocatalytic selectivity of the reaction were not reported in this work.

Proust et al. [97] investigated the interaction of POMs with $\mathrm{CO}_{2}$ in acetonitrile. The electrolysis of a $\mathrm{CO}_{2}$-saturated, $(\mathrm{TOA})_{6}\left[\alpha-\mathrm{SiW}_{11} \mathrm{O}_{39} \mathrm{Co}\left({ }_{-}\right)\right]$(TOA = tetraoctyl ammonium) dichloromethane solution, at $-1.5 \mathrm{~V}$ vs. $\mathrm{Hg}_{2} \mathrm{Cl}_{2} / \mathrm{Hg}(1 \mathrm{M} \mathrm{LiCl})$ on a $\mathrm{Hg}$ working electrode, revealed that $\mathrm{CO}_{2}$ could be reduced to $\mathrm{CO}$ with a low faradaic yield of $18 \%$ and no $\mathrm{H}_{2}$ by-product. The introduction of an extra proton source $\left(\mathrm{TBAHSO}_{4}\right)$ into this electrolysis system, resulted in the detection of a $4 \mathrm{e} / 4 \mathrm{H}$ reduction product, formaldehyde, along with $\mathrm{CO}$. The faradaic efficiency for this reaction reached up to $25 \%$ while the turnover number (TON) was 1.75. Interestingly, the authors found that a trace amount of formaldehyde was detected after electrolysis of a $(\mathrm{TOA})_{6}\left[\mathrm{SiW}_{11} \mathrm{O}_{39} \mathrm{Co}\left({ }_{-}\right)\right]$solution under argon; the likely source of carbon in this case was the solvent, $\mathrm{CH}_{2} \mathrm{Cl}_{2}$. This illustrated the important role of isotope-labeled $\mathrm{CO}_{2}$ in determining the carbon source of the electrocatalytic $\mathrm{CO}_{2} \mathrm{RR}$ products. Although the efficiency of this system was low, the relatively systematic investigation process demonstrated the working conditions of polyoxoanions in electrocatalytic $\mathrm{CO}_{2} \mathrm{RRs}$, explored the reaction efficiency and the product species, and illustrated the important role of the proton source (in the electrolyte) in electrocatalytic $\mathrm{CO}_{2}$ reduction over polyoxoanions. It is worth noting that the electrocatalytic reduction of $\mathrm{CO}_{2}$ to formaldehyde over $\left(\mathrm{TOA}_{6}{ }_{6}\left[\mathrm{SiW}_{11} \mathrm{O}_{39} \mathrm{Co}\left({ }_{-}\right)\right]\right.$is very rare. A promising research avenue is the further exploration of different types of POMs and TM substitutes to achieve the highly selective reduction of $\mathrm{CO}_{2}$ to formaldehyde.

These works demonstrate the metalloporphyrin-like reactivity of POMs in nonpolar electrolytes and explain the activation pathways of $\mathrm{CO}_{2}$ molecules and the reason for the loss of activity over TM-substituted POMs in aqueous electrolytes. Accordingly, the development of metalloporphyrin-like POMs with heterogeneous, stable active sites in aqueous electrolytes is essential to achieving highly efficient, highly selective, POM-based electrocatalytic $\mathrm{CO}_{2}$ reduction in the future. Using TM-substituted POMs to understand the process of $\mathrm{CO}_{2}$ reduction activated by TM complexes may also provide design and guiding principles for the development of new heterogeneous metalloporphyrin electrocatalysts and metalloporphyrin-like, single-atom electrocatalysts.

Besides TM-substituted POMs, metal-organic complexes with $\mathrm{CO}_{2} \mathrm{RR}$ activity can also be introduced into the structure of POMs. Inspired by this idea, Proust's team grafted $\left[\mathrm{Cp}^{*} \mathrm{Rh}^{\mathrm{III}}(\mathrm{bpy}) \mathrm{Cl}\right]^{+}\left(\mathrm{Cp}^{*}=\right.$ pentamethylcyclopentadienyl anion, bpy $=2,2^{\prime}$ - bipyridine) with $\mathrm{CO}_{2} \mathrm{RR}$ activity to vacant $\alpha-\mathrm{H}_{2} \mathrm{PW}_{11} \mathrm{O}_{39}$ polyoxoanions to construct a (TBA) ${ }_{3}\left[\mathrm{H}_{2} \mathrm{PW}_{11} \mathrm{O}_{39}\left\{\mathrm{Rh}^{\mathrm{III}} \mathrm{Cp}^{*}\left(\mathrm{OH}_{2}\right)\right\}\right]$ catalyst for electrocatalytic $\mathrm{CO}_{2} \mathrm{RR}$ in an acetonitrile solution (Fig. 3) [98]. $\left[\mathrm{H}_{2} \mathrm{PW}_{11} \mathrm{O}_{39}\left\{\mathrm{Rh}^{\mathrm{II}} \mathrm{Cp}^{*}\left(\mathrm{OH}_{2}\right)\right\}\right]^{3-}$ exhibited poorer electrocatalytic $\mathrm{CO}_{2} \mathrm{RR}$ activity than that of the parent $\left[\mathrm{Cp}^{*} \mathrm{Rh}{ }^{\mathrm{III}}(\mathrm{bpy}) \mathrm{Cl}\right]^{+}$catalyst, and the Faraday efficiency (FE) for the $\mathrm{CO}_{2} \mathrm{RR}$ product, $\mathrm{HCOOH}$, was only $4.5 \%$. However, the FE for the by-product $\mathrm{H}_{2}$ was as high as $68 \%$. Under the same conditions, the $\mathrm{FE}$ for $\mathrm{CO}_{2}$ reduction to $\mathrm{HCOOH}$ on $\left[\mathrm{Cp}^{*} \mathrm{Rh}^{\mathrm{III}}(\mathrm{bpy}) \mathrm{Cl}\right]^{+}$was $60 \%$ while that of the by-product, $\mathrm{H}_{2}$, was only $30 \%$. This result suggests that the strategy of replacing the bpy group with polyoxoanions adversely affects the electrocatalytic $\mathrm{CO}_{2} \mathrm{RRs}$. The low $\mathrm{FE}$ of the electrocatalytic $\mathrm{CO}_{2} \mathrm{RRs}$ may result from the reduction of the
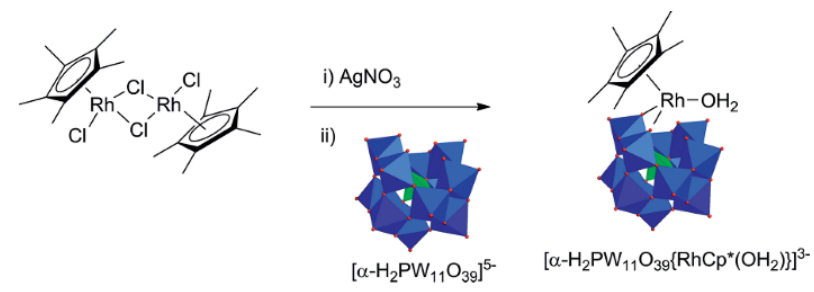

Fig. 3. Synthesis of the organometallic derivative $\left[\alpha-\mathrm{H}_{2} \mathrm{PW}_{11} \mathrm{O}_{39}\left\{\mathrm{Rh}^{\mathrm{III}} \mathrm{Cp}^{*}\left(\mathrm{OH}_{2}\right)\right\}\right]^{3-}$ (the POM skeleton is displayed in polyhedral representation). Reprinted with the permission of Ref. [98]. Copyright 2019 WILEY-VCH Verlag GmbH \& Co. KGaA, Weinheim. 
polyoxoanions themselves and the protons stored by the reduced POMs. This work provides some guidelines for the reasonable ligand-modification of bipyridyl-based molecular catalysts.

The above facts indicate that substituted polyoxoanions can, to a certain extent, perform electrocatalytic $\mathrm{CO}_{2} \mathrm{RRs}$. These substituted polyoxoanions can be used as homogeneous catalysts in organic electrolytes for electrocatalytic $\mathrm{CO}_{2} \mathrm{RRs}$; despite the reaction efficiency, the selectivity and FE is very poor. These works achieved limited success in the application of polyoxoanions in electrocatalytic $\mathrm{CO}_{2} \mathrm{RRs}$ but, considering the well-defined structures, adjustable composition and redox properties, could inform the design and optimization principles of molecular electrocatalysts for $\mathrm{CO}_{2} \mathrm{RRs}$. Therefore, polyoxoanions can be used to elucidate the electron transfer process and the activity origin in electrocatalytic $\mathrm{CO}_{2} \mathrm{RR}$ processes at a molecular level, and potentially regulate the selectivity and activity of molecular catalysts.

\subsection{POM-based organic-inorganic hybrids for electrocatalytic $\mathrm{CO}_{2} \mathrm{RRS}$}

Due to the high solubility of polyoxoanions in aqueous solutions, the design of insoluble POM-based heterogeneous catalysts is considered another feasible approach to promoting its application in electrocatalytic $\mathrm{CO}_{2} \mathrm{RR}$. The use of POMs to construct organic-inorganic hybrids can not only significantly reduce the solubility of POMs, but also integrate the functional characteristics of organic molecular catalysts for $\mathrm{CO}_{2} \mathrm{RRs}$ into polyoxoanions, which presents an ideal strategy for designing POM-based hybrid materials for electrocatalytic $\mathrm{CO}_{2} \mathrm{RRs}$ [99].

Metalloporphyrin compounds are a typical kind of catalyst for electrocatalytic $\mathrm{CO}_{2} \mathrm{RRs}$ often used for electrocatalytic $\mathrm{CO}_{2}$ reduction in organic solvents. Isaacs et al. [100] modified an indium tin oxide (ITO) electrode with M- $\mu$-(meso-5,10,15,20-tetra(pirydil)porphyrin)tetrakis\{bis(bip
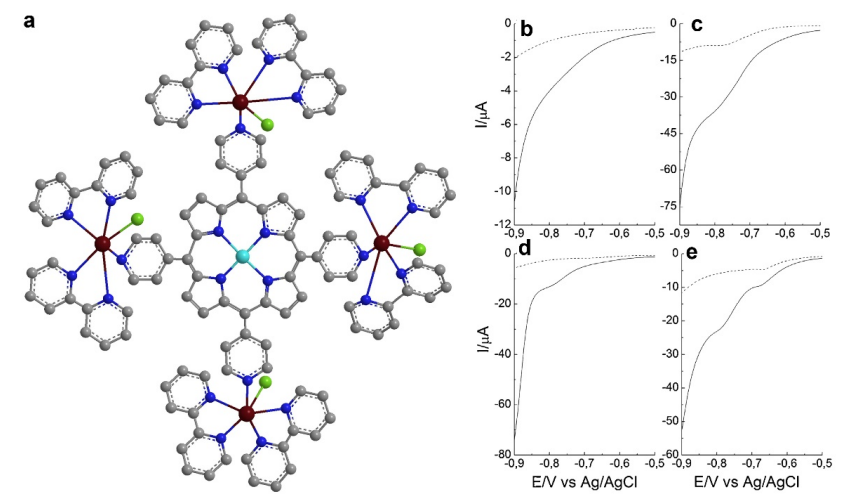

Fig. 4. (a) Structural representation of $\mathrm{Mn}(\mathrm{III}), \mathrm{Ni}(\mathrm{II})$, and $\mathrm{Zn}(\mathrm{II})$ $\mu$-(meso-5,10,15,20-tetra(pirydil)porphyrin)tetrakis\{bis(bipyridine)chl oride ruthenium(II)\}; Linear sweep voltammogram of bare ITO electrode (b), [Mn $\left.{ }^{\text {IIITRP }}\right]^{5+} /\left[\mathrm{SiW}_{12} \mathrm{O}_{40}\right]^{4-}$ multilayer modified electrode (c) $\left[\mathrm{Zn}^{\mathrm{IITRP}}\right]^{4+} /\left[\mathrm{SiW}_{12} \mathrm{O}_{40}\right]^{4-}$ multilayer modified electrode $(\mathrm{d})$ and $\left[\mathrm{Ni}{ }^{I I T R P}\right]^{4+} /\left[\mathrm{SiW}_{12} \mathrm{O}_{40}\right]^{4-}$ multilayer modified electrode the in presence (solid line) and absence (dash line) of $\mathrm{CO}_{2}$ and $0.1 \mathrm{M} \mathrm{NaClO}_{4}$ solution at $5 \mathrm{mV} \mathrm{s}^{-1}$ (e). Reprinted with the permission of Ref. [100]. Copyright 2013 Elsevier Ltd.
Table 2

Electrocatalytic $\mathrm{CO}_{2} \mathrm{RR}$ activity and products of [MTRP]/[SiW $\left.{ }_{12} \mathrm{O}_{40}\right] / \mathrm{ITO}$ electrodes.

\begin{tabular}{|c|c|c|c|}
\hline \multirow{2}{*}{ Electrode } & \multicolumn{3}{|c|}{ Products and TOF $\left(\mathrm{s}^{-1}\right)$} \\
\hline & $\mathrm{CO}$ & $\mathrm{HCOOH}$ & $\mathrm{CH}_{3} \mathrm{OH}$ \\
\hline$\left[\mathrm{Mn}^{\text {IIITRP }}\right]^{5-} /\left[\mathrm{SiW}_{12} \mathrm{O}_{40}\right]^{4-} / \mathrm{ITO}$ & N.D. ${ }^{\mathrm{a}}$ & $0.48^{b}$ & 0.023 \\
\hline$\left[\mathrm{Zn}^{\mathrm{IITRP}}\right]^{5-} /\left[\mathrm{SiW}_{12} \mathrm{O}_{40}\right]^{4-} / \mathrm{ITO}$ & 0.0037 & N.D. ${ }^{a}$ & 8.2 \\
\hline$\left[\mathrm{Ni}^{\mathrm{IITRP}}\right]^{5-} /\left[\mathrm{SiW}_{12} \mathrm{O}_{40}\right]^{4-} / \mathrm{ITO}$ & 0.24 & 0.083 & N.D. a \\
\hline
\end{tabular}

a means that no product was detected; ${ }^{b}$ the values in red are the main products.

yridine)chloride ruthenium(II)\} (MTRP, $\mathrm{M}=\mathrm{Mn}, \mathrm{Zn}$, Ni, Fig. $4(\mathrm{a})$ ) and $\left[\mathrm{SiW}_{12} \mathrm{O}_{40}\right]^{4-}$ polyoxoanions using a layer-by-layer method (LBL), and studied the electrocatalytic $\mathrm{CO}_{2} \mathrm{RR}$ activities of the modified electrodes in a $\mathrm{NaClO}_{4}$ electrolyte.

The TM cation in the metalloporphyrin complex can significantly affect the species and selectivity of the electrocatalytic $\mathrm{CO}_{2} \mathrm{RR}$ product (Fig. 4(b)-(e)), as shown in Table 2. $\left[\mathrm{Mn}^{\text {IIITRP }}\right]^{5-} /\left[\mathrm{SiW}_{12} \mathrm{O}_{40}\right]^{4-} / \mathrm{ITO}$ induces electrocatalytic $\mathrm{CO}_{2}$ reduction to formic acid and methanol at a potential of $-0.8 \mathrm{~V}$ vs. $\mathrm{Ag} / \mathrm{AgCl}$ (and turnover frequency (TOF) of 0.48 and 0.023 $\mathrm{s}^{-1}$ respectively), no $\mathrm{CO}$ is produced. The main electrocatalytic $\mathrm{CO}_{2} \mathrm{RR}$ product using [Zn $\left.{ }^{\mathrm{IITRP}}\right]^{5-} /\left[\mathrm{SiW}_{12} \mathrm{O}_{40}\right]^{4-} / \mathrm{ITO}$ is methanol (TOF $=8.2 \mathrm{~s}^{-1}$ ), while the TOF of CO is only $0.0037 \mathrm{~s}^{-1}$ and the formation of formic acid is not detected.

The use of $\left[\mathrm{NiITRP}^{5-}{ }^{-} /\left[\mathrm{SiW}_{12} \mathrm{O}_{40}\right]^{4-} / \mathrm{ITO}\right.$ in electrocatalytic $\mathrm{CO}_{2} \mathrm{RRs}$ primarily produces $\mathrm{CO}$ (TOF $=0.24 \mathrm{~s}^{-1}$ ), while only a small amount of formic acid is produced (TOF $=0.083 \mathrm{~s}^{-1}$ ) and no methanol is detected. Interestingly, under light irradiation, $\left[\mathrm{Mn}^{\text {IIITRP }}\right]^{5-} /\left[\mathrm{SiW}_{12} \mathrm{O}_{40}\right]^{4-} /$ ITO can reduce $\mathrm{CO}_{2}$ to formaldehyde at a potential of $-0.65 \mathrm{~V}$ vs. $\mathrm{Ag} / \mathrm{AgCl}\left(\mathrm{TOF}=16.7 \mathrm{~s}^{-1}\right)$. The above results indicate that photo-generated electrons can improve the electron transfer process of the catalyst and change the electrocatalytic $\mathrm{CO}_{2} \mathrm{RR}$ products from $\mathrm{CO}$ (a 2-electron reduced product) to formaldehyde (a 4-electron reduced product), possibly the result of the electron transfer from the $\mathrm{Ru}$ (bipy) ${ }_{2} \mathrm{Cl}^{+}$ component to the metalloporphyrin component. These results demonstrate that the central cations of metalloporphyrin complexes can regulate the electrocatalytic $\mathrm{CO}_{2} \mathrm{RR}$ product and selectivity; moreover, the deep reduction of $\mathrm{CO}_{2}$ and the acceleration of the reaction rate can be achieved under light conditions. The improved electron transfer in the electrocatalytic $\mathrm{CO}_{2}$ reduction process under light conditions may be related to the electron storage characteristics of POMs. It appears that photoelectric $\mathrm{CO}_{2}$ reduction uses electrons efficiently and can achieve deep reduction of $\mathrm{CO}_{2}$. However, this hypothesis requires evidence showing the electron transfer process from the POMs to $\mathrm{CO}_{2}$ molecules, and the Faraday efficiency of the electrocatalysis in this system needs clarification.

On this basis, Lan's group [37] prepared a series of stable polyoxometalate-metalloporphyrin organic framework (PMOF) materials consisting of Zn- $\varepsilon$-Keggin POM $\quad(\{\varepsilon-$ $\left.\left.\mathrm{PMo}_{8} \mathrm{VMo}_{4}{ }^{\mathrm{VI}} \mathrm{O}_{40} \mathrm{Zn}_{4}\right\}\right)$ and M-tetrakis[4-carboxyphenyl] -porphyrin (M-TCPP, M=Co, Fe, Ni) via a hydrothermal method for electrocatalytic $\mathrm{CO}_{2} \mathrm{RRs}$ in aqueous electrolyte solutions $\left(\mathrm{KHCO}_{3}\right.$, Fig. 5(a)). The researchers found that the TMs in the PMOFs significantly influence the catalysts' performances in 
$\mathbf{a}$
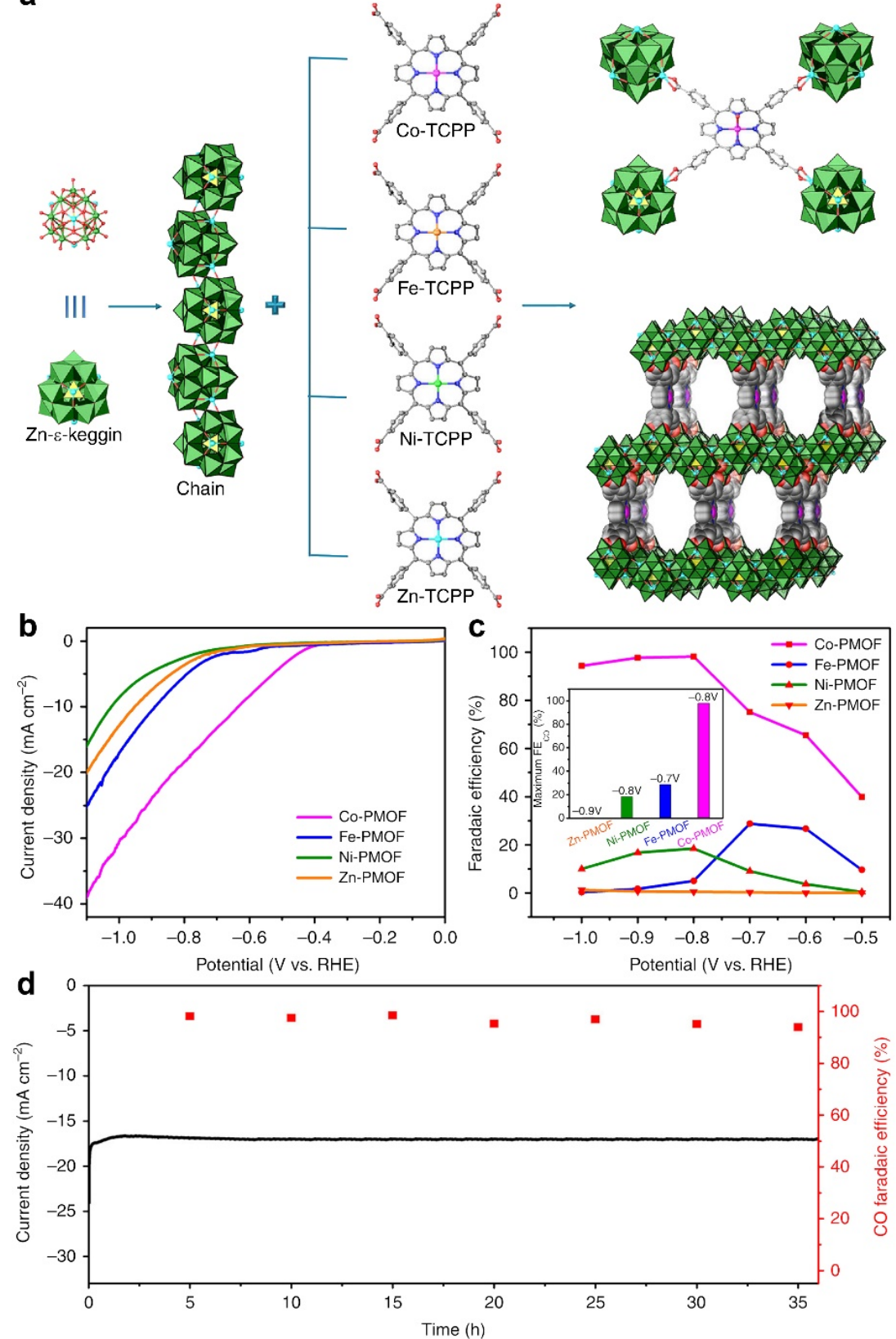

Fig. 5. (a) Schematic illustration of the structures of M-PMOFs (M = Co, Fe, Ni, Zn). M-PMOFs consist of 4-connection TCPP linkers and zigzag POM chains; (b) Linear sweep voltammetry (LSV) curves of M-PMOFs; (c) Faradaic efficiencies for CO; (d) Durability test of Co-PMOF at a potential of -0.8 V vs. RHE. Reprinted with the permission of Ref. [37]. Copyright 2018, Springer Nature.

electrocatalytic $\mathrm{CO}_{2}$ RRs (Figs. 5(b)-(c)). The Co-modified PMOF achieved the highest $\mathrm{CO}_{2} \mathrm{RR}$ activity, reducing $\mathrm{CO}_{2}$ to $\mathrm{CO}$ at a potential of $-0.8 \mathrm{~V} v$ s. RHE and showing excellent stability over 36 hours (Fig. 5(d)). The FE for CO was 99\% and the TOF was $1656 \mathrm{~h}^{-1}$. DFT calculations have also been used to investigate the increased activity of Co-PMOFs, refer to Section 4.5. This work demonstrated for the first time that POM-based materials can achieve highly efficient electrocatalytic $\mathrm{CO}_{2} \mathrm{RRs}$ in aqueous electrolytes, and the use of isotope-labeled ${ }^{13} \mathrm{CO}_{2}$ proved that the carbon source of the reduction product was $\mathrm{CO}_{2}$ molecules. These results may provide new perspectives on the regulation of electrocatalytic performance of metalloporphyrin molecular catalysts in aqueous electrolytes. Since the electrocatalytic $\mathrm{CO}_{2} \mathrm{RR}$ activity of this series of PMOFs originates from the M-TCPP component, the regulatory effects of the different POMs in these composite systems require further research.

In addition to metalloporphyrin compounds, manganese carbonyl compounds are also typical catalysts for electrocatalytic $\mathrm{CO}_{2} \mathrm{RRs}$, however, they can only function as homogeneous catalysts in organic electrolytes. Recently, our group selected a carbonyl manganese bipyridine complex ([Mn'(bipyridyl)(CO) $\left.\left.{ }_{3} \mathrm{Br}\right], a b b r . \mathrm{MnL}\right)$ and $\mathrm{POMs}$ to prepare three POM-MnL composite electrocatalysts (SiW $12-\mathrm{MnL}$, $\mathrm{PW}_{12}-\mathrm{MnL}$, and $\mathrm{SiW}_{12}-\mathrm{MnL}$, Fig. 6(a)) [101]. By combining 


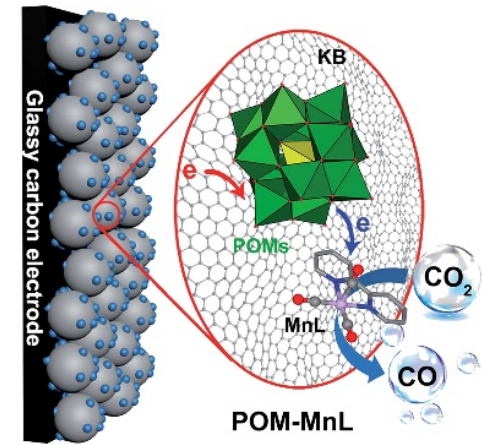

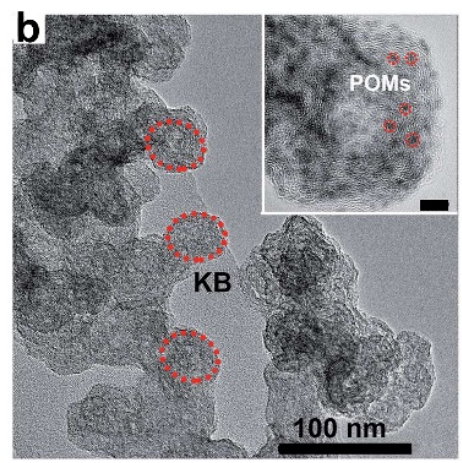
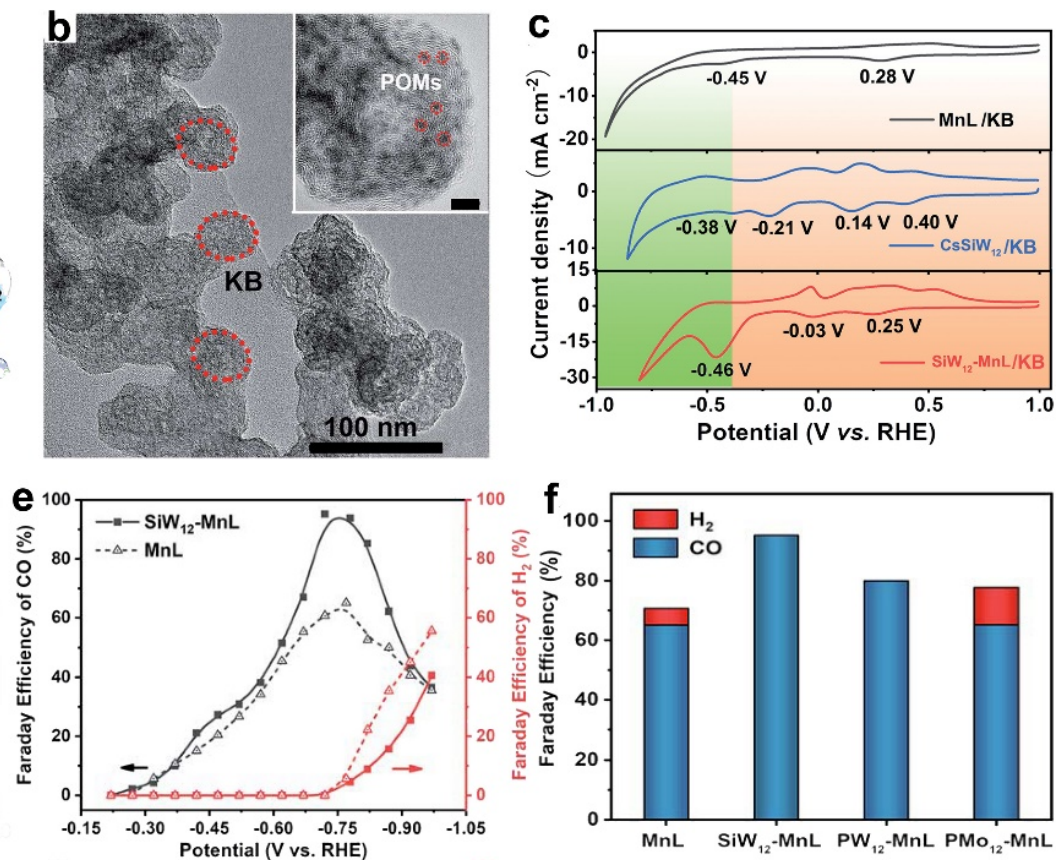

Fig. 6. (a) Schematic diagram of the reaction mechanism induced by POM-MnL; (b) TEM image of SiW ${ }_{12}-\mathrm{MnL} / \mathrm{KB}$ (inset: HR-TEM image of $\mathrm{SiW}_{12}-\mathrm{MnL} / \mathrm{KB}$, scale bar: $5 \mathrm{~nm}$ ); (c) The CV curves for MnL/KB, CsSiW $12 / \mathrm{KB}$, and $\mathrm{SiW}_{12}-\mathrm{MnL} / \mathrm{KB}$ in $0.5 \mathrm{~mol} \mathrm{~L}^{-1} \mathrm{~N}_{2}$-saturated $\mathrm{KHCO}_{3}$ at a $0.05 \mathrm{~V} \mathrm{~s}^{-1} \mathrm{scan}$ rate; (d) The $\mathrm{LSV}$ curves of $\mathrm{SiW}_{12}-\mathrm{MnL} / \mathrm{KB}$ and $\mathrm{MnL} / \mathrm{KB}$ in $0.5 \mathrm{M} \mathrm{N}_{2}$-(black curve) or $\mathrm{CO}_{2}$-(red curve) saturated $\mathrm{KHCO}_{3}$ electrolyte; (e) The $\mathrm{FE}$ for $\mathrm{CO}$ at different potentials for $\mathrm{MnL} / \mathrm{KB}$ and $\mathrm{SiW}_{12}-\mathrm{MnL} / \mathrm{KB}$ (the line is drawn only to guide the eye); (f) The FEs for $\mathrm{CO}$ and $\mathrm{H}_{2}$ at the overpotential of the highest FE for CO of MnL/KB and POM-MnL/KB. Reprinted with the permission of Ref. [101]. Copyright 2020, Royal Society of Chemistry (RSC).

POM-MnL with Ketjen Black (KB), the conductivity of POM-MnL can be increased for use in electrocatalytic $\mathrm{CO}_{2}$ reduction (Fig. 6(b)). This POM-MnL composite catalyst system demonstrated electron storage ability (Fig. 6(c)) and low solubility in aqueous electrolytes; it was, therefore, expected to function as a heterogeneous catalyst for electrocatalytic $\mathrm{CO}_{2} \mathrm{RRs}$. In the $\mathrm{KHCO}_{3}$ electrolyte, $\mathrm{SiW}_{12}-\mathrm{MnL}$ achieves the best electrocatalytic $\mathrm{CO}_{2} \mathrm{RR}$ activity. $\mathrm{SiW}_{12}$-MnL achieves a significantly improved FE for $\mathrm{CO}$ (at $-0.72 \mathrm{~V}$ vs. RHE potential) of $95 \%$ (compared to the $65 \%$ achieved by the parent $\mathrm{MnL}$ ) and a reduced $\mathrm{FE}$ for $\mathrm{H}_{2}$ (Figs. 6(d)-(f)). Conversely, $\mathrm{PMo}_{12}$-MnL exhibits poor electrocatalytic $\mathrm{CO}_{2} \mathrm{RR}$ activity, in which the hydrogen evolution reactions (HERs) and the $\mathrm{CO}_{2} \mathrm{RRs}$ occur simultaneously. The $\mathrm{FE}$ for $\mathrm{CO}$ is approximately $65 \%$, while the $\mathrm{FE}$ of $\mathrm{H}_{2}$ is $12 \%$ (Fig. 6(f)). In addition, $\mathrm{SiW}_{12}$-MnL functions stably for $12 \mathrm{~h}$ in a $0.5 \mathrm{M} \mathrm{KHCO}_{3}$ electrolyte, and the FE for CO remained stable above 95\%. A series of electrochemical experiments, DFT calculations (discussed in detail in Section 4.5), and transient spectroscopy characterization confirmed that the electron transfer processes between POMs and MnL units differ, depending on the type of $\mathrm{POM}$, and that a highly efficient electron transfer process from POM to MnL increases the FE for $\mathrm{CO}$ and reduces the FE for $\mathrm{H}_{2}$. This work not only realized heterogenous MnL, which allows the MnL to achieve efficient electrocatalytic $\mathrm{CO}_{2} \mathrm{RRs}$ in aqueous electrolytes, but also confirmed the effect of the electron transfer process between POMs and MnL components on electrocatalytic $\mathrm{CO}_{2} \mathrm{RRs}$, providing several insights into the synergistic effect of multi-component molecular electrocatalysts in terms of electron transfer. However, this work did not provide in-situ experimental characterization to prove the reaction process of
POM and MnL during electrochemical $\mathrm{CO}_{2} \mathrm{RRs}$ and was unable to achieve the deep reduction of $\mathrm{CO}_{2}$ to multielectron products using the electron-storage capability of POMs.

The above studies demonstrated series of POM-based organic-inorganic molecular hybrid catalysts used in electrocatalytic $\mathrm{CO}_{2} \mathrm{RRs}$. The combination of POMs and organic molecular catalysts with $\mathrm{CO}_{2} \mathrm{RR}$ activity via electrostatic, covalent, or coordination interaction, can significantly reduce the solubility of POMs and organic molecular catalysts in the electrolyte and achieve heterogeneous POM-organic molecular catalysts. Moreover, the POMs can drive electron transfer to the organic molecular components during electrocatalytic $\mathrm{CO}_{2} \mathrm{RRs}$, to assist the organic molecular catalyst in catalyzing the $\mathrm{CO}_{2} \mathrm{RRs}$ in the aqueous electrolyte, significantly improving electrocatalytic $\mathrm{CO}_{2} \mathrm{RR}$ selectivity, and suppressing side reactions. These works offer some explanations of the activity origin of multi-component, multi-center composite electrocatalysts, reveal several factors that affect their electrocatalytic performance in $\mathrm{CO}_{2} \mathrm{RRs}$ on a molecular scale, and finally provide a deeper understanding of the electron transfer process during electrocatalytic $\mathrm{CO}_{2}$ reduction. Nevertheless, the electron transfer processes of POMs cannot change the type of $\mathrm{CO}_{2} \mathrm{RR}$ products catalyzed by the organic molecular catalyst to realize the deep reduction of $\mathrm{CO}_{2}$ to high-value, multielectron products.

\subsection{POMs as electrolytes for electrocatalytic $\mathrm{CO}_{2} \mathrm{RR}$}

POMs are considered good electron/proton carriers due to their good solubility and adjustable redox activity in solvents, which can be employed as electron/proton buffer solutions. 


$$
\begin{aligned}
\mathrm{SiW}^{4-} \stackrel{+\mathrm{e}^{-}}{\rightleftharpoons-\mathrm{e}^{-}} \mathrm{SiW}^{5-} \stackrel{+\mathrm{e}^{-}}{\stackrel{\mathrm{e}^{-}}{\longrightarrow}} \mathrm{SiW}^{6-} \stackrel{+\mathrm{e}^{-}}{\rightleftharpoons} \underset{-\mathrm{e}^{-}}{\|} \mathrm{SiW}^{7-} \\
-\mathrm{CO}_{2}\left\|+\mathrm{CO}_{2}-\mathrm{CO}_{2}\right\|+\mathrm{CO}_{2} \\
\mathrm{SiW}^{6-}-\mathrm{CO}_{2} \stackrel{+\mathrm{e}^{-}}{\rightleftharpoons-\mathrm{e}^{-}} \mathrm{SiW}^{7-}-\mathrm{CO}_{2}
\end{aligned}
$$

Fig. 7. Square reaction scheme representing the interaction between the reduced forms of $\left[\alpha-\mathrm{SiW}_{12} \mathrm{O}_{40}\right]^{4-}$ and $\mathrm{CO}_{2}$ during electrochemical reduction. $\left[\alpha-\mathrm{SiW}_{12} \mathrm{O}_{40}\right]^{4-}$ is represented as $\mathrm{SiW}^{4^{-}}$for convenience. Reprinted with the permission of Ref. [102]. Copyright 2016 WILEY-VCH Verlag GmbH \& Co. KGaA, Weinheim.

Accordingly, POMs are regarded as a new kind of electrolyte with electronic regulation effects. As explained in Section 4.1, the activity of TM-substituted POMs in nonpolar solutions is owed to the coordinated unsaturated substitute metal atoms. When TM-substituted POMs are present in an aqueous electrolyte, the water molecules will preferentially coordinate with the TM active sites of the TM-substituted POMs, inhibiting the electrocatalytic $\mathrm{CO}_{2}$ reduction activity of the TM atoms. Saturated POMs are similar to the oxides of Mo or W, which do not have electrocatalytic $\mathrm{CO}_{2} \mathrm{RR}$ activity. Therefore, unlike the POM-based homogeneous molecular electrocatalysts used for electrocatalytic $\mathrm{CO}_{2} \mathrm{RR}$, POMs serving as electrolytes often have no electrocatalytic $\mathrm{CO}_{2} \mathrm{RR}$ activity in the electrolyte, but can significantly increase the $\mathrm{CO}_{2} \mathrm{RR}$ activity of other catalysts.

Given the good solvent compatibility, favorable structural stability, and redox activity (in a certain $\mathrm{pH}$ range) of POMs, Zhang et al. [102] first studied the electrocatalytic $\mathrm{CO}_{2} \mathrm{RR}$ activity of Ag nanoparticles stabilized with bovine serum albumin
(AgNC@BSA) in $\left[\mathrm{SiW}_{12} \mathrm{O}_{40}\right]^{4-}$ containing dimethylformamide (DMF) electrolyte. As shown in Fig. 7, $\left[\mathrm{SiW}_{12} \mathrm{O}_{40}\right]^{4-}$ anions as electron transfer medium strongly interacts with $\mathrm{CO}_{2}$ molecules, promoting electron transfer between the electrode and AgNC@BSA. This process is similar to the reduction processes of the redox enzyme in nature. Finally, the AgNC@BSA efficiently catalyzes the reduction of $\mathrm{CO}_{2}$ to $\mathrm{CO}$. The study recorded a FE for CO up to $75.6 \%$. The AgNC@BSA demonstrated good stability, a slight decrease of approximately $20 \%$ in the current magnitude was observed over a period of 20000 s. In general, this study employed electrochemical CV to analyze the role of POMs as electron transfer media in detail, which has recently been confirmed to be consistent with their role in other $\mathrm{CO}_{2} \mathrm{RR}$ electrolytes. Therefore, using POMs with different structures and compositions as a model facilitates the systematic study of the effects of electrolytes on electrocatalytic $\mathrm{CO}_{2} \mathrm{RRs}$. However, the electron transfer process from $\mathrm{SiW}_{12}$ to AgNC@BSA during the electrocatalytic $\mathrm{CO}_{2}$ reduction process requires further in-situ characterization to prove.

Subsequently, Li's group $[103,104]$ studied the electrocatalytic $\mathrm{CO}_{2} \mathrm{RR}$ activity of the In electrode in aqueous solutions containing $\mathrm{SiW}_{9} \mathrm{~V}_{3}$ and $\mathrm{SiW}_{11} \mathrm{Mn}$ POMs as electrolytes. In the POM electrolyte, the In electrode not only induces the electrocatalytic reduction of $\mathrm{CO}_{2}$ to $\mathrm{C} 1$ compounds such as $\mathrm{CO}$ and formic acid, but the $\mathrm{C} 2$ product, acetic acid, is also detected. As shown in Fig. 8(a), in the $\mathrm{SiW}_{9} \mathrm{~V}_{3}$ electrolyte, the In electrode induces electrocatalytic $\mathrm{CO}_{2} \mathrm{RRs}$ at a potential of $-0.71 \mathrm{~V} v \mathrm{~s}$. RHE (pH 4.07) and the FE for the product acetic acid reaches 96.5\%. Whereas in the $\mathrm{SiW}_{11} \mathrm{Mn}$ electrolyte, the In electrode induces the electrocatalytic reduction of $\mathrm{CO}_{2}$ to acetic acid at a
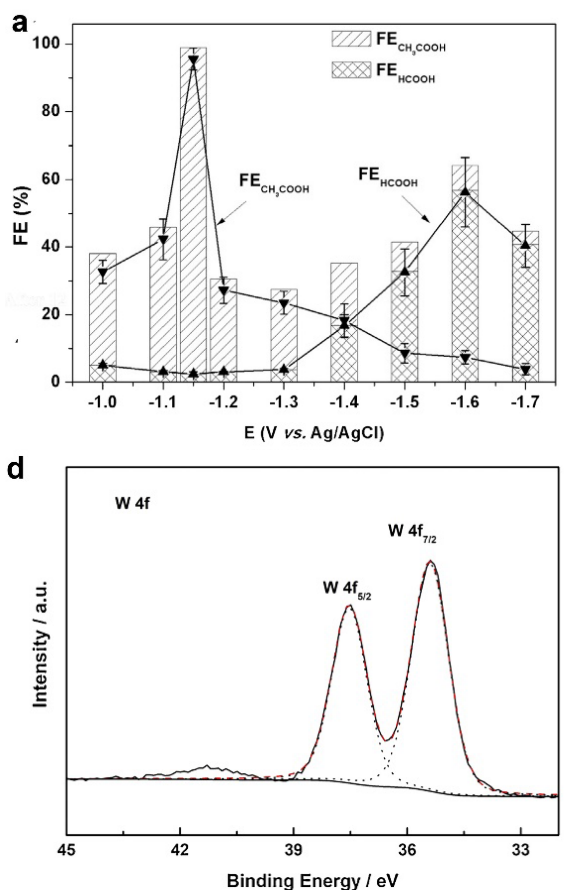
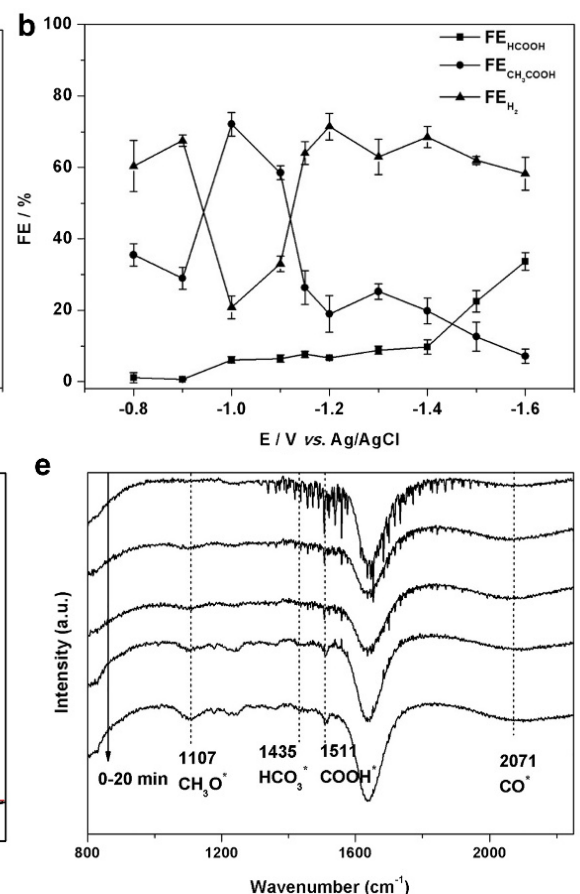

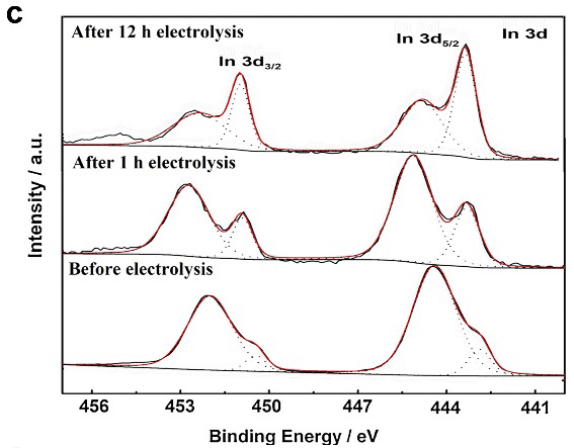

$\mathbf{f}$

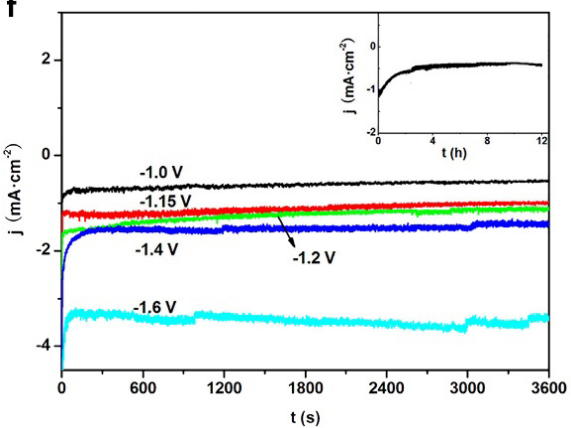

Fig. 8. The Faradaic efficiencies of products of In cathode in $\mathrm{SiW}_{9} \mathrm{~V}_{3}$ (a) and $\mathrm{SiW}_{11} \mathrm{Mn}$ (b) electrolyte. (c) XPS spectra of In $3 d$ for the indium electrode before and after electrolysis with 1 and $12 \mathrm{~h}$. (d) XPS spectra of W $4 f$ for the indium electrode after $1 \mathrm{~h}$ electrolysis. (e) The FTIR spectroscopy characterization for the $2 \mathrm{mM} \mathrm{SiW}_{9} \mathrm{~V}_{3}-0.1 \mathrm{M} \mathrm{Na}_{2} \mathrm{SO}_{4}$ electrolyte during electrolysis, in which the peak at $2071 \mathrm{~cm}^{-1}$ corresponds to the adsorbed CO*. (f) Current density with electrolysis time at different potential for $1 \mathrm{~h}$; The inset is the current density with electrolysis time at $-1.15 \mathrm{~V} v s$. Ag/AgCl for 12 h. Reprinted with the permission of Refs. [103,104]. Copyright 2020 Elsevier Ltd. 
potential of $-0.55 \mathrm{~V} v s$. RHE ( $\mathrm{pH} 4.07$ ) and the FE for acetic acid reaches $72.1 \%$ (Fig. 8(b)). X-ray photoelectron spectroscopy (XPS) and in-situ IR spectroscopy were used to study the reaction of the In electrode surface during the electrocatalytic $\mathrm{CO}_{2}$ reduction process in order to infer the possible reaction mechanism. As shown in Figs. 8(c)-(d), after the electrocatalytic $\mathrm{CO}_{2}$ reduction reaction, the concentration of the oxide species on the surface of the In electrode has decreased, while the $\mathrm{W}^{6+}$ species has formed on the electrode surface. The formation of In- $\mathrm{CO}_{2}{ }^{*}$ intermediates was detected through in-situ IR spectroscopy (Fig. 8(e)), indicating that the In electrode is at the center of activated $\mathrm{CO}_{2}$. Based on the electrochemical CV, XPS, and IR spectroscopy results, it was inferred that the reduction process of $\mathrm{W}$ in POMs improves the selectivity of the In electrode in catalyzing the reduction of $\mathrm{CO}_{2}$ to acetic acid through the electron transfer path in the electrolyte. In addition, the POM-assisted, In-electrode catalyzed $\mathrm{CO}_{2}$ reduction is stable for at least $12 \mathrm{~h}$ (Fig. 8(f)). This investigation proves the electron transfer process between the POM solution and the metal electrode, and achieved the deep reduction of $\mathrm{CO}_{2}$ on an In electrode, thus increasing the selectivity of the $\mathrm{C} 2$ product. This work provides a new way to optimize the product selectivity of electrocatalytic $\mathrm{CO}_{2} \mathrm{RRs}$, in terms of electrolyte solutions, and offers some guidance for designing electrolytes that can be used for the deep reduction of $\mathrm{CO}_{2}$ based on in-situ experiments and mechanism research.

\subsection{POM-involved nanocomposite electrocatalysts for $\mathrm{CO}_{2} \mathrm{RRS}$}

In addition to their excellent electrochemical activity and redox properties, POMs have also attracted great attention in the field of materials chemistry due to their rich structures and composition characteristics. The elements found in POMs include not only the aforementioned TMs, but also metals in the $d$ block, $d s$ block, $f$ block, and even the $p$ block. The molecular scale of POMs can be adjusted from sub-nanometer to hundreds of nanometers. In addition, POMs are widely recognized as a reducing agent and stabilizer for the preparation of nanomaterials. These characteristics of POMs make them ideal precursors for the preparation of efficient $\mathrm{CO}_{2} \mathrm{RR}$ nano-electrocatalysts.

Zhang's group [105] used $\mathrm{PMo}_{12} \mathrm{O}_{40^{3-}}$ as a stabilizer and prepared a Ag-[PMo $\mathrm{PMO}_{20} \mathrm{O}_{40}{ }^{n-}(\mathrm{Ag}-\mathrm{PMo})$ nanocomposite through electrochemical deposition. As shown in Figs. 9(a) and (b), Ag-PMo forms a dendritic structure of nano-silver, PMo12 polyoxoanions can be adsorbed onto the surface of the nano-silver to reduce the adsorption energy and further stabilize the structure of nano-Ag. The porous 3D structure of Ag-PMo promotes access to the catalytic active center, enhancing the catalytic performance during $\mathrm{CO}_{2} \mathrm{RRs}$ (Fig. 9(c)). In a DMF electrolyte, Ag-PMo nanocomposites induced highly selective electrocatalytic $\mathrm{CO}_{2} \mathrm{RRs}$. The onset potential of the Ag-PMo nanocomposite electrode during $\mathrm{CO}_{2} \mathrm{RRs}$ was found to be more positive than that of an $\mathrm{Ag}$ polycrystalline electrode (about $700 \mathrm{mV}$ ), and $\mathrm{Ag}$-PMo reduced $\mathrm{CO}_{2}$ to $\mathrm{CO}$ with a $\mathrm{FE}$ of about $90 \%$ over a wide potential range. The mechanism study showed that $\mathrm{PMo}_{12}$ promotes the adsorption and stabilization of $\mathrm{CO}_{2}$ intermedi-
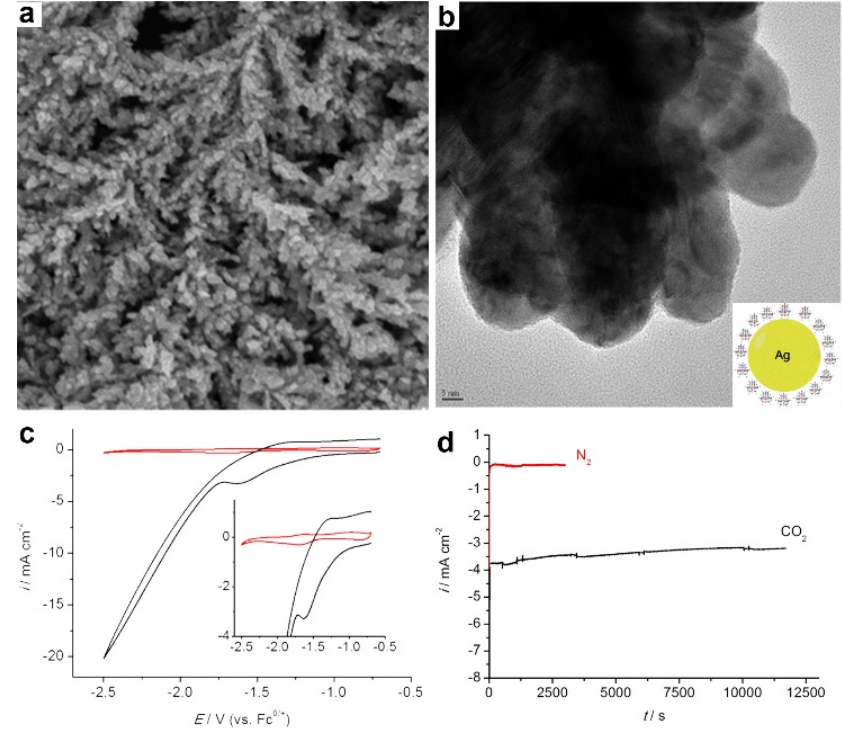

Fig. 9. (a) SEM images of Ag-PMo nanocomposite-modified ITO glasses; (b) TEM images of Ag-PMo nanocomposites, inset: Schematic diagram of Ag-PMo catalytic $\mathrm{CO}_{2}$ reduction; (c) Comparison of cyclic voltammograms obtained at an Ag-PMo nanocomposite-modified GC electrode in DMF $\left(0.1 \mathrm{M}\left[n-\mathrm{Bu}_{4} \mathrm{~N}\right] \mathrm{PF}_{6}\right)$ with $0.5 \%(v / v)$ added $\mathrm{H}_{2} \mathrm{O}$ under a $\mathrm{CO}_{2}$ (black line) or a $\mathrm{N}_{2} \mathrm{~b}$ (red line) atmosphere (Scan rate: $100 \mathrm{mV} \mathrm{s}^{-1}$ ); (d) Potentiostatic $i$ - $t$ curves obtained at an Ag-PMo nanocomposite modified GC electrode in DMF $\left(0.1 \mathrm{M}\left[n-\mathrm{Bu}_{4} \mathrm{~N}\right] \mathrm{PF}_{6}\right)$ with $0.5 \%(v / v)$ added water under $\mathrm{CO}_{2}$ or $\mathrm{N}_{2}$ atmospheres. Applied potential: $-1.9 \mathrm{~V} v \mathrm{v}$. $\mathrm{Fc}^{0 /+}$. Reprinted with the permission of Ref. [105]. Copyright 2018, American Chemical Society.

ates, which decrease the overpotential, suppress the occurrence of side reactions, and improve the electrocatalytic $\mathrm{CO}_{2} \mathrm{RR}$ activity. The POM-modified Ag nanoparticles remained stable for more than three hours (Fig. 9(d)). This work illustrates the role of POMs in POM-involved nanocomposites for electrocatalytic $\mathrm{CO}_{2} \mathrm{RRs}$, that is, POMs serve as Lewis bases to interact with $\mathrm{CO}_{2}$ molecules in a Lewis acid-base interaction, which stabilizes the key intermediates in the $\mathrm{CO}_{2} \mathrm{RRs}$, and promotes the activity of Ag toward electrocatalytic $\mathrm{CO}_{2} \mathrm{RRs}$. However, the introduction of POMs still cannot deepen the reduction of $\mathrm{CO}_{2}$ induced by the Ag catalyst, the main product is still 2-electron reduced CO.

Subsequently, Zhang and co-workers [106] used PMo12 as a protective agent in the production of ultra-thin Bi nanosheets under electrodeposition conditions. The obtained nanocomposite was used for the electrocatalytic reduction of $\mathrm{CO}_{2}$ to formic acid in aqueous electrolytes. Using bipotential electrodeposition, the $\mathrm{PMo}_{12}$ polyoxoanions in the electrolyte interact with the $\mathrm{Bi}^{3+}$ cations through electrostatic interaction to promote the electroreduction of $\mathrm{Bi}^{3+}$ to form an ultra-thin $(4 \mathrm{~nm})$ porous 3D structure (Bi-PMo, Figs. 10(a) and (b)). In the absence of $\mathrm{PMo}_{2}, \mathrm{Bi}^{3+}$ can only form a nano-dendritic structure under electrochemical reduction conditions. Raman spectroscopy (Fig. 10(c)) show that Bi-PMo nanosheets do not produce the characteristic peak of $\mathrm{PMo}_{12}$, suggesting that during the preparation of the Bi-PMo nanosheets, the POMs may have decomposed. XPS spectra (Figs. 10(d) and (e)) indicate that the Mo in Bi-PMo exists in the form of $\mathrm{MoO}_{x}$ species. CV experiments (Fig. 

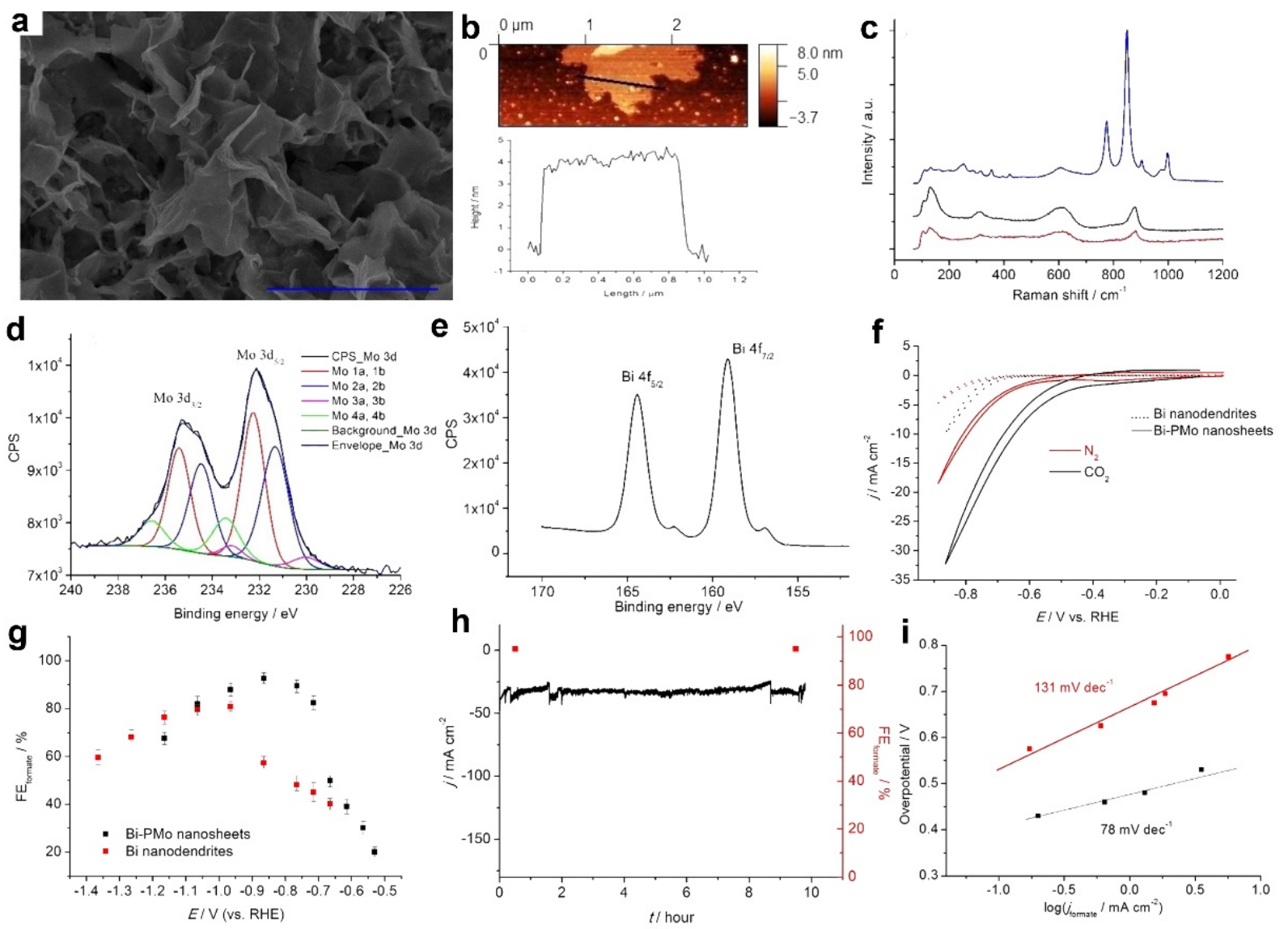

Fig. 10. (a) SEM image of the film deposited on an FTO electrode in aqueous $0.25 \mathrm{M} \mathrm{HNO}_{3}$ solutions containing 1.0 mM Bi(NO $)_{3}$; (b) Atomic force microscopy (AFM) image and height profile of Bi-PMo nanosheets; (c) Raman spectra of Bi-PMo nanosheets before (black) and after electrolysis (red), and $\mathrm{H}_{3} \mathrm{PMo}_{12} \mathrm{O}_{40}$ (blue); (d,e) High-resolution XPS spectra recorded for Mo $3 d$ and $\mathrm{Bi} 4 f$ regions of the Bi-PMo nanosheets; (f) Cyclic voltammograms obtained for Bi-PMo nanosheet (solid lines) and Bi nano-dendrite (dash lines) modified GC electrodes in $\mathrm{CO}_{2}$-(black) or $\mathrm{N}_{2}$-(red) saturated 0.5 M Na$\mathrm{HCO}_{3}$ aqueous solutions, scan rate: $0.1 \mathrm{~V} \mathrm{~s}^{-1}$; (g) Faradaic efficiencies for formate produced on Bi-PMo nanosheets (black) and Bi nano-dendrites (red) at various applied potentials in $\mathrm{CO}_{2}$-saturated $0.5 \mathrm{M} \mathrm{NaHCO}_{3}$ solutions; (h) Long term stability study of Bi-PMo nanosheets during controlled potential electrolysis at $-0.86 \mathrm{~V}$ vs. RHE in a $\mathrm{CO}_{2}$-saturated $0.5 \mathrm{M} \mathrm{NaHCO}_{3}$ solution; (i) Tafel plots obtained for Bi-PMo nanosheets (black) and Bi nano-dendrites (red). Reprinted with the permission of Ref. [106]. Copyright 2019 Wiley-VCH Verlag GmbH \& Co. KGaA, Weinheim.

10 (f)) show that both $\mathrm{Bi}$ nanomaterials demonstrate $\mathrm{CO}_{2}$ reduction activity. As shown in Fig. 10(g), in aqueous electrolyte solution ( $\left.0.5 \mathrm{M} \mathrm{KHCO}_{3}\right)$, the ultra-thin Bi nanosheets selectively reduce $\mathrm{CO}_{2}$ to formic acid with a $\mathrm{FE}$ of $93 \%$ at a potential of $-0.86 \mathrm{~V}$ vs. RHE. Compared with the performances of $\mathrm{Bi}$ nano-dendrites, the overpotential of ultra-thin Bi nanosheets is $300 \mathrm{mV}$ less, the $\mathrm{FE}$ for formic acid is $10 \%$ greater, and the $\mathrm{FE}$ for $\mathrm{H}_{2}$ (resulting from side reactions) is suppressed. The catalytic activity of Bi-PMo is maintained for at least $10 \mathrm{~h}$ (Fig. 10(h)). The mechanism study (Tafel curve; Fig. 10(i)) found that the rate-limiting step of the process on ultra-thin $\mathrm{Bi}$ nanosheets is the protonation of the $\mathrm{CO}^{*}$ intermediate, while the rate-limiting step of the process on Bi nano-dendrites is the formation of $\mathrm{CO}^{*-}$. The geometry of the ultra-thin Bi nanosheets, provides more reaction sites for the adsorption of $\mathrm{CO}_{2}$, which promotes the formation of $\mathrm{CO}^{*}$ intermediates, reduces the overpotential, and increases the FE for formic acid. Although the $\mathrm{PMo}_{12}$ decomposed during the electrocatalytic $\mathrm{CO}_{2} \mathrm{RRs}$, the electron transfer process and the electrostatic interaction between $\mathrm{PMo}_{12}$ and $\mathrm{Bi}^{3+}$ ensured the formation of $\mathrm{Bi}$ nanosheets, which provides new avenues for the design and synthesis of
POM-derived electrocatalysts. This work demonstrates a new approach to the preparation of electrocatalytic $\mathrm{CO}_{2}$ reduction catalysts, with unique morphologies, using POMs. The performances of the reported POM-based electrocatalysts are compared with those of state-of-the-art electrocatalytic $\mathrm{CO}_{2}$ reduction systems in Table 3.

\subsection{DFT calculations of POM-based electrocatalysts for $\mathrm{CO}_{2} \mathrm{RRS}$}

DFT is a powerful tool used to reveal key information of electrocatalytic $\mathrm{CO}_{2} \mathrm{RRs}$, including the geometric structures, electronic structures, adsorption characteristics, and electron transfer processes, which can well reveal the reactivity and mechanisms of $\mathrm{CO}_{2} \mathrm{RRs}$.

Lan et al. [37] used DFT calculations to illustrate the catalytic activity of different TM-modified PMOFs in terms of the adsorption free energy of key steps in the electrocatalytic $\mathrm{CO}_{2} \mathrm{RRs}$. During the assembly of Zn- $\varepsilon$-Keggin and Co-TCPP, the Co-PMOF exhibits remarkably lower $\Delta G_{1}$ and $\Delta G_{2}$ (Figs. 11(a) and (b)), which is consistent with the electroreduction activity and selectivity tendency of this PMOF. The reaction mechanism, based 
Table 3

Performance of major POM-based electrocatalysts and other representative electrocatalysts used in electrocatalytic $\mathrm{CO}_{2} \mathrm{RRs}$.

\begin{tabular}{|c|c|c|c|c|c|c|}
\hline Electrocatalyst & Electrolyte & Potential & Principal product & $\mathrm{FE}(\%)$ & TON & Ref. \\
\hline$(\mathrm{TOA})_{6}\left[\alpha-\mathrm{SiW}_{11} \mathrm{O}_{39} \mathrm{Co}\left(\_\right)\right]$ & $\mathrm{CH}_{2} \mathrm{Cl}_{2}$ & $-1.5 \mathrm{~V}$ vs. $\mathrm{Hg}_{2} \mathrm{Cl}_{2} / \mathrm{Hg}$ & $\mathrm{CO}$ & 18 & - & [97] \\
\hline$(\mathrm{TBA})_{3}\left[\mathrm{H}_{2} \mathrm{PW}_{11} \mathrm{O}_{39}\left\{\mathrm{Rh}^{\mathrm{III}} \mathrm{Cp}^{*}\left(\mathrm{OH}_{2}\right)\right\}\right]$ & $\mathrm{CH}_{3} \mathrm{CN}$ & $-1.8 \mathrm{~V}$ vs. $\mathrm{Hg}_{2} \mathrm{Cl}_{2} / \mathrm{Hg}$ & $\mathrm{HCOOH}$ & 4.5 & 0.8 & [98] \\
\hline$\left[\mathrm{Cp} * \mathrm{Rh}^{\mathrm{III}}(\mathrm{bpy}) \mathrm{Cl}\right]^{+}$ & $\mathrm{CH}_{3} \mathrm{CN}$ & $-1.8 \mathrm{~V}$ vs. $\mathrm{Hg}_{2} \mathrm{Cl}_{2} / \mathrm{Hg}$ & $\mathrm{HCOOH}$ & 60 & 18 & [98] \\
\hline$[\mathrm{Mn}(\mathrm{III}) \mathrm{TRP}]^{5+} /\left[\mathrm{SiW}_{12} \mathrm{O}_{40}\right]^{4^{-}} / \mathrm{ITO}$ & $0.1 \mathrm{M} \mathrm{NaClO}_{4}$ & $-0.8 \mathrm{~V}$ vs. Ag/AgCl & $\mathrm{HCOOH}$ & - & $1.06 \times 10^{4}$ & {$[100]$} \\
\hline$[\mathrm{Zn}(\mathrm{II}) \mathrm{TRP}]^{4+} /\left[\mathrm{SiW}_{12} \mathrm{O}_{40}\right]^{4^{-}} / \mathrm{ITO}$ & $0.1 \mathrm{M} \mathrm{NaClO}_{4}$ & $-0.8 \mathrm{~V}$ vs. Ag/AgCl & Methanol & - & $1.76 \times 10^{5}$ & {$[100]$} \\
\hline$[\mathrm{Ni}(\mathrm{II}) \mathrm{TRP}]^{5+} /\left[\mathrm{SiW}_{12} \mathrm{O}_{40}\right]^{4^{-}} / \mathrm{ITO}$ & $0.1 \mathrm{M} \mathrm{NaClO}_{4}$ & $-0.8 \mathrm{~V}$ vs. $\mathrm{Ag} / \mathrm{AgCl}$ & $\mathrm{CO}$ & - & $3.85 \times 10^{3}$ & {$[100]$} \\
\hline$[\mathrm{Ni}(\mathrm{II}) \mathrm{TRP}]^{5+}$ & DMF & $-0.8 \mathrm{~V}$ vs. SHE & $\mathrm{CO}$ & - & - & {$[107]$} \\
\hline Co-PMOF & $0.5 \mathrm{M} \mathrm{KHCO}_{3}$ & $-0.8 \mathrm{~V}$ vs. RHE & $\mathrm{CO}$ & 98.7 & 7693 & [37] \\
\hline Fe-PMOF & $0.5 \mathrm{M} \mathrm{KHCO}_{3}$ & $-0.8 \mathrm{~V}$ vs. RHE & $\mathrm{CO}$ & 28.8 & - & [37] \\
\hline $\mathrm{Ni}-\mathrm{PMOF}$ & $0.5 \mathrm{M} \mathrm{KHCO}_{3}$ & -0.8 V vs. RHE & $\mathrm{CO}$ & 18.5 & - & [37] \\
\hline Zn-PMOF & $0.5 \mathrm{M} \mathrm{KHCO}_{3}$ & $-0.8 \mathrm{~V} v s . \mathrm{RHE}$ & $\mathrm{CO}$ & 0.95 & - & {$[37]$} \\
\hline Сo-ТMCP & $0.5 \mathrm{M} \mathrm{KHCO}_{3}$ & $-0.9 \mathrm{~V} v s . \mathrm{RHE}$ & $\mathrm{CO}$ & $\sim 50$ & - & {$[37]$} \\
\hline MOF-525(Co) & $0.5 \mathrm{M} \mathrm{KHCO}_{3}$ & $-0.8 \mathrm{~V} v s . \mathrm{RHE}$ & $\mathrm{CO}$ & 47.9 & - & {$[37]$} \\
\hline CoPPC/CNT & $0.5 \mathrm{M} \mathrm{KHCO}_{3}$ & $-0.58 \mathrm{~V} v s . \mathrm{RHE}$ & $\mathrm{CO}$ & $\sim 90$ & - & {$[108]$} \\
\hline $\mathrm{SiW}_{12}-\mathrm{MnL} / \mathrm{KB}$ & $0.5 \mathrm{M} \mathrm{KHCO}_{3}$ & $-0.72 \mathrm{~V} v s . \mathrm{RHE}$ & $\mathrm{CO}$ & 95 & - & {$[101]$} \\
\hline $\mathrm{PW}_{12}-\mathrm{MnL} / \mathrm{KB}$ & $0.5 \mathrm{M} \mathrm{KHCO}_{3}$ & $-0.72 \mathrm{~V} v s . \mathrm{RHE}$ & $\mathrm{CO}$ & 80 & - & {$[101]$} \\
\hline $\mathrm{PMo}_{12}-\mathrm{MnL} / \mathrm{KB}$ & $0.5 \mathrm{M} \mathrm{KHCO}_{3}$ & $-0.52 \mathrm{~V} v s . \mathrm{RHE}$ & $\mathrm{CO}$ & 65 & - & [101] \\
\hline $\mathrm{MnL} / \mathrm{KB}$ & $0.5 \mathrm{M} \mathrm{KHCO}_{3}$ & $-0.72 \mathrm{~V} v s . \mathrm{RHE}$ & $\mathrm{CO}$ & 65 & - & {$[101]$} \\
\hline$\left[\mathrm{Mn}(\mathrm{L})(\mathrm{CO})_{3} \mathrm{Br}(\mathrm{MnL})\right.$ & $\mathrm{CH}_{3} \mathrm{CN}$ & $-1.7 \mathrm{~V} v s . \mathrm{Ag} / \mathrm{Ag}^{+}$ & $\mathrm{CO}$ & 85 & 34 & [109] \\
\hline AgNC@BSA & $1 \mathrm{mM}\left[\mathrm{Bu}_{4} \mathrm{~N}\right]_{4}\left[\alpha-\mathrm{SiW}_{12} \mathrm{O}_{40}\right]$ in DMF & $-2.32 \mathrm{~V} v s . \mathrm{Fc}^{0 /+}$ & $\mathrm{CO}$ & 75.6 & - & {$[102]$} \\
\hline Ag-PMo & DMF & -1.9 vs. $\mathrm{Fc}^{0 /+}$ & $\mathrm{CO}$ & $90 \pm 5$ & - & {$[105]$} \\
\hline Ag/N-doped graphene/carbon foam & $0.1 \mathrm{M} \mathrm{KHCO}_{3}$ & $-0.6 \mathrm{~V} v s . \mathrm{RHE}$ & Ethanol & 85.2 & - & {$[110]$} \\
\hline Ag QDDCs & $0.5 \mathrm{M} \mathrm{KHCO}_{3}$ & -0.3 V vs. RHE & $\mathrm{CO}$ & 95 & - & {$[111]$} \\
\hline Indium sheet & $2 \mathrm{mM} \mathrm{SiW}_{9} \mathrm{~V}_{3}+0.1 \mathrm{M} \mathrm{Na}_{2} \mathrm{SO}_{4}$ & -1.15 vs. $\mathrm{Ag} / \mathrm{AgCl}$ & $\mathrm{CH}_{3} \mathrm{COOH}$ & 96.5 & - & [103] \\
\hline Indium sheet & $2 \mathrm{mM} \mathrm{SiW}_{11} \mathrm{Mn}+0.1 \mathrm{M} \mathrm{Na}_{2} \mathrm{SO}_{4}$ & $-1.0 \mathrm{~V} v s . \mathrm{RHE}$ & $\mathrm{CH}_{3} \mathrm{COOH}$ & 72.1 & - & {$[104]$} \\
\hline $\mathrm{In}_{2} \mathrm{O}_{3}-\mathrm{rGO}$ & $0.1 \mathrm{M} \mathrm{KHCO}_{3}$ & -1.2 V vs. RHE & $\mathrm{HCOOH}$ & 84.6 & - & {$[112]$} \\
\hline Sulfur-doped indium & $0.5 \mathrm{M} \mathrm{KHCO}_{3}$ & -0.98 V vs. RHE & $\mathrm{HCOOH}$ & 93 & - & [113] \\
\hline Bi-PMo nanosheets & $0.5 \mathrm{M} \mathrm{KHCO}_{3}$ & -0.86 V vs. RHE & $\mathrm{CH}_{3} \mathrm{COOH}$ & 93 & - & [105] \\
\hline Bi nano-dendrites & $0.5 \mathrm{M} \mathrm{KHCO}_{3}$ & $-0.96 \mathrm{~V} v s . \mathrm{RHE}$ & $\mathrm{CH}_{3} \mathrm{COOH}$ & 81 & - & [105] \\
\hline Bi nanoflakes & $0.1 \mathrm{M} \mathrm{KHCO}_{3}$ & $-0.6 \mathrm{~V} v s . \mathrm{RHE}$ & $\mathrm{HCOOH}$ & $\sim 100$ & - & [114] \\
\hline
\end{tabular}

- indicates that the data is not given.

on the DFT calculations, suggest that the POM components first accept electrons in the electrochemical process of $\mathrm{CO}_{2} \mathrm{RR}$ (Fig. 11(c) and (d)), these electrons then transfer to the Co-TCPP units, which promotes the electrocatalytic $\mathrm{CO}_{2} \mathrm{RR}$ activity on TCPP, therefore, the Co-PMOF shows higher catalytic activity than the parent Co-TCPP. This work uses DFT calculations to reveal the electrocatalytic $\mathrm{CO}_{2}$ reduction activity of PMOFs modified with different metals in terms of the free energy of the electron/proton transfer step, which agree well with the experimental results. These DFT calculations provide a theoretical basis for revealing the regulation of catalyst activity during $\mathrm{CO}_{2} \mathrm{RRs}$.

Since electrocatalytic $\mathrm{CO}_{2}$ reduction involves a complex electron transfer process, and the electron transfer process during electrocatalysis is very rapid and involves multiple time scales, DFT is an effective tool for studying the electron transfer processes in electrocatalytic $\mathrm{CO}_{2}$ RRs. Our research group and collaborators used DFT, in combination with transient spectroscopy experiments, to study the electron transfer process of different types of POMs and manganese carbonyl compounds $(\mathrm{MnL})$, which revealed the reason for the synergistic effect of the electrocatalytic $\mathrm{CO}_{2}$ reduction activity over POM-MnL. As shown in Fig. 12(a), analysis of the molecular orbital energy of
POM-MnL revealed that after POM is introduced into MnL, the lowest unoccupied molecular orbital (LUMO) of POM-MnL has complete participation of the $\mathrm{W}(4 \mathrm{~d})$ and $\mathrm{O}(2 \mathrm{p})$ orbitals from the POM, which indicates that during electrocatalytic $\mathrm{CO}_{2} \mathrm{RRs}$, the POM units preferentially accept electrons, and only once the LUMO of the POM is filled does the MnL center undergo electrochemical reduction. This process has been confirmed through electrochemical CV, refer to Section 4.2, Fig. 6(c) for details. In order to reveal the electron transfer process between POM and MnL, the electronic structures of POM-MnL with different degrees of reduction were calculated. As shown in Fig. 12(b), when POM-MnL undergoes 4-electron reduction, the electrons stored on the POMs spontaneously transfer to the $\mathrm{MnL}$ component. Electron transfer to the MnL component occurs most easily in $\mathrm{SiW}_{12}$ POM and least easily in $\mathrm{PMo}_{12}$ POM. This electron transfer process is also captured by a transient photovoltage spectrum (Fig. 12(b)). In terms of energy, the $\mathrm{SiW}_{12} \mathrm{POM}$ has the lowest activation energy toward electrocatalytic $\mathrm{CO}_{2} \mathrm{RRs}$ (Fig. 12(d)). This work reveals in detail the reduction process and electron transfer process of the multi-component electrocatalysts for electrocatalytic $\mathrm{CO}_{2}$ reduction through DFT and experimental spectroscopy characterization and provides new insights for understanding the synergistic 
a

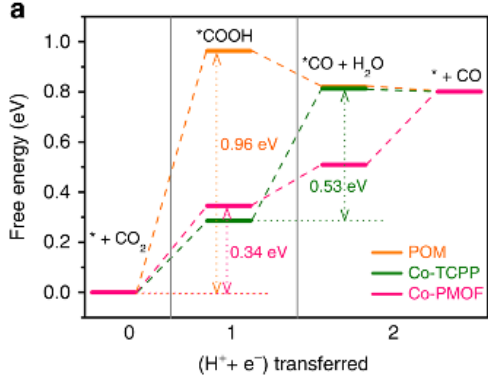

c

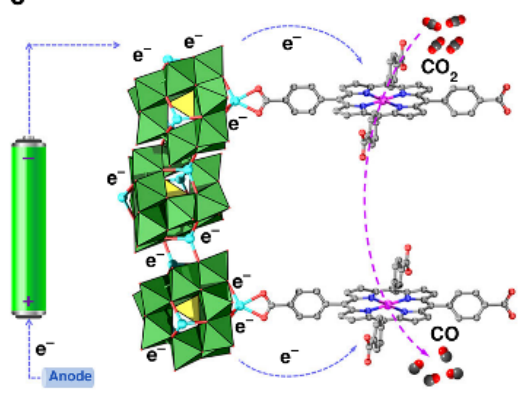

b

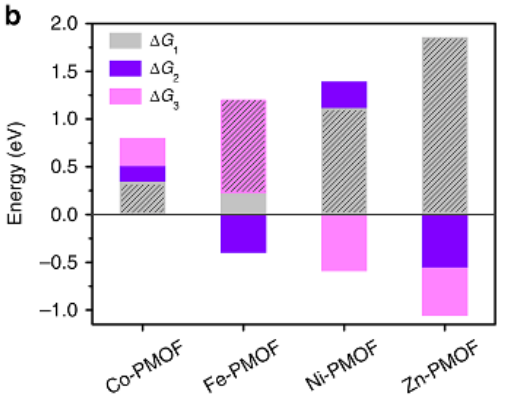

d

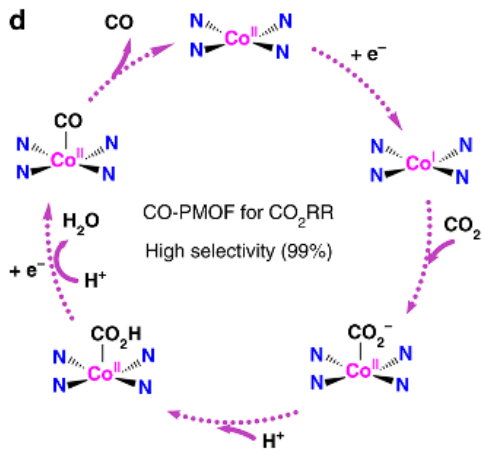

Fig. 11. The DFT calculation and proposed reaction mechanism. (a) The free energy diagrams of $\mathrm{CO}_{2}$ reduction to $\mathrm{CO}$ for POM (orange), Co-TCPP (green), and Co-PMOF (pink). The rate-determining step and the corresponding free energy of each material are indicated (Note that an asterisk represents a surface-active site for reaction); (b) Comparison of the free energy of each elementary reaction $\left(\Delta G_{1}, \Delta G_{2}\right.$, and $\Delta G_{3}$ represent the free energy of ${ }^{*} \mathrm{COOH}$ formation, ${ }^{*} \mathrm{CO}$ formation, and $\mathrm{CO}$ desorption, respectively) during $\mathrm{CO}_{2} \mathrm{RRs}$ for Co-PMOF, Fe-PMOF, Ni-PMOF, and Zn-PMOF, respectively; $(\mathrm{c}, \mathrm{d})$ Proposed mechanism scheme for the $\mathrm{CO}_{2} \mathrm{RRs}$ on Co-PMOF (POMs as electron-donors, porphyrins as charge transfer ligands, and TMs as electron-acceptors). Reprinted with the permission of Ref. [37]. Copyright 2018, Springer Nature.

effect of multi-component electrocatalysts and the electron transfer process of POM-based electrocatalysts.

\section{Conclusions and prospects}

Owing to the substantial overlap of polyoxometalate chemistry with material chemistry and catalytic chemistry, the application of polyoxometalates in the field of energy conversion field increasing, especially in electrocatalysis [115-118]. Informing the rapid development of POMs in electrocatalytic carbon dioxide reduction, are their ability to serve as models used to facilitate the understanding of key adsorption and activation processes of $\mathrm{CO}_{2}$ reduction, the involved important intermediates, and the electron/proton transfer pathways, which provides important guidelines for the design of efficient and highly selective electrocatalysts for electrocatalytic $\mathrm{CO}_{2} \mathrm{RRs}$.

In this review, we highlight the advances in POM-based electrocatalysts for electrocatalytic $\mathrm{CO}_{2}$ reduction and illustrate the key roles played by POMs in electrocatalytic $\mathrm{CO}_{2} \mathrm{RRs}$, providing insights into understanding the mechanism regulating electrocatalytic $\mathrm{CO}_{2} \mathrm{RR}$ activity and selectivity. Despite the enormous progress that has been made in the development of POM-based electrocatalysts for $\mathrm{CO}_{2}$ reduction, as outlined in this review, the important roles of POMs in the electrocatalytic process and the key steps involved in the electrocatalytic $\mathrm{CO}_{2} \mathrm{RRs}$ over POMs require further clarification. Several challenges must be overcome in order to scale-up POM electrocatalysts for industrial application.

(1) Although the adsorption sites and activation modes of
$\mathrm{CO}_{2}$ molecules on POM molecules are relatively clear, the adsorption-activation pathway of $\mathrm{CO}_{2}$ as well as the rate-determining step on POM-based nanomaterials and nanoclusters require elucidation.

(2) While POMs are known to exhibit reversible electron storage and transfer behavior, owing to the rapid electron transfer kinetics of electrocatalytic reactions, the direct observation and capture of these processes are very difficult using conventional characterization methods $[119,120]$. Moreover, the electron transfer processes in electrocatalytic reactions are very complicated, involving intra-molecular, intermolecular, interfacial, and catalyst-reaction substrate electron transfer. Clarifying the mechanisms of these electron transfer processes is not only of scientific significance but can also offer rational guidance to optimizing and improving the reaction efficiency towards specific products of electrocatalytic $\mathrm{CO}_{2} \mathrm{RRs}$.

(3) The good solubility of POMs is an advantage in homogeneous catalysis but a disadvantage in composite heterogeneous electrocatalysts, since the dissolution of POM species during electrocatalysis deactivates the electrocatalysts. The stabilization of POM molecular structures requires specific conditions; some POMs are only stable in acidic environments, and decompose under neutral or alkaline conditions. However, due to the weak acidity of $\mathrm{CO}_{2}$, the electrolyte used for $\mathrm{CO}_{2}$ reduction is often neutral or alkaline, which benefits to the dissolution of $\mathrm{CO}_{2}$ molecules. The development of polyoxometalates that are stable under electrocatalytic carbon dioxide reduction is a pressing challenge.

We speculate on possible solutions to these challenges and 


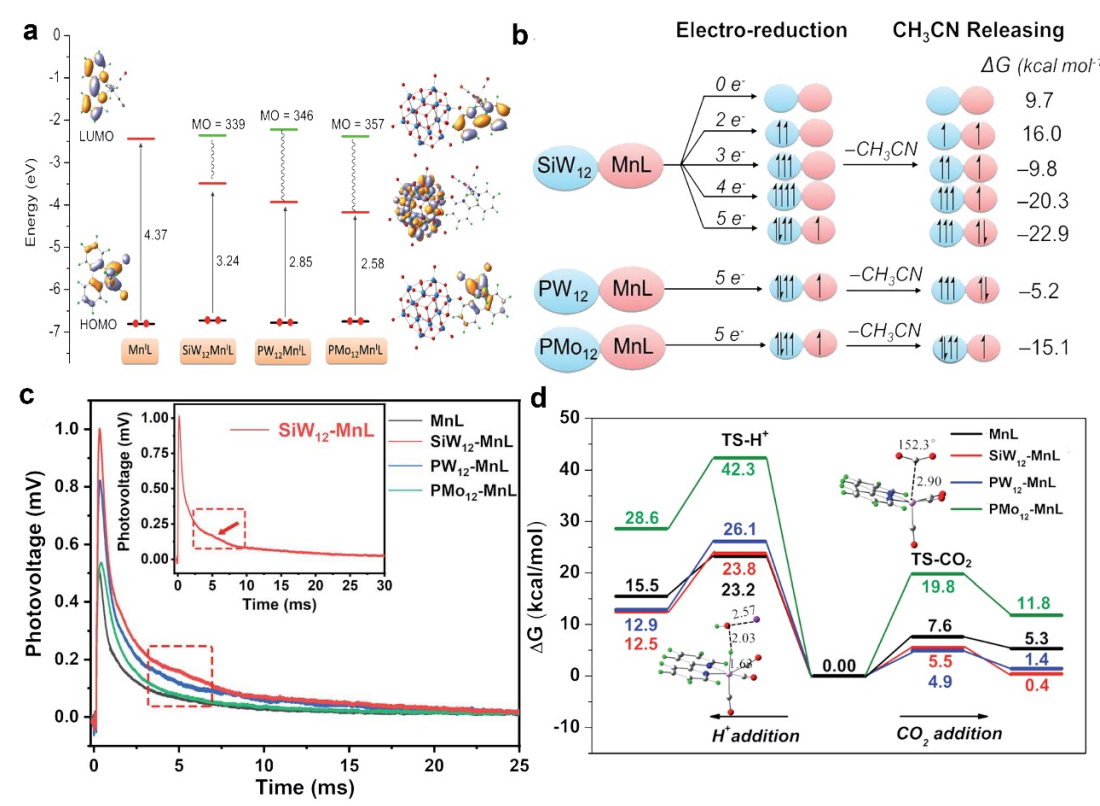

Fig. 12. (a) Computed frontier orbitals (compositions and energies) for MnL, SiW 12 -MnL, PW 12 -MnL, and PMo12-MnL (the green lines represent the unoccupied molecular orbitals (MO) contributed by MnL in POM-MnL); (b) The electronic configurations for the different reduction degree states of $\mathrm{SiW}_{12}-\mathrm{MnL}, \mathrm{PW}_{12}-\mathrm{MnL}$, and $\mathrm{PMo}_{12}-\mathrm{MnL}$; (c) The transient photovoltage curves of powder POM-MnL and MnL; (d) Potential energy surfaces for $\mathrm{H}^{+}$and $\mathrm{CO}_{2}$ addition to the respective active $\mathrm{CO}_{2}$ and $\mathrm{H}$ adducts. Reprinted with the permission of Ref. [101]. Copyright 2020, Royal Society of Chemistry (RSC).

suggest development directions that should be focused on. By taking full advantage of the POM model to inform an in-depth understanding of the key influencing factors of electrocatalytic $\mathrm{CO}_{2} \mathrm{RRs}$, a blueprint for the design of efficient and highly selective $\mathrm{CO}_{2} \mathrm{RR}$ electrocatalyst can be derived.

(1) $\mathrm{CO}_{2}$ adsorption and activation are the most important factors affecting the activity and selectivity of electrocatalytic $\mathrm{CO}_{2} \mathrm{RRs}$, however, it is very difficult to observe these adsorption intermediate states. On the one hand, POMs can be used to clarify the characteristics of molecular structures, which, combined with computational chemistry, can be used to establish a scientific theoretical model for theoretical research. On the other hand, in-situ, time-resolved characterization techniques such as in-situ XPS, in-situ IR spectroscopy, and in-situ Raman spectroscopy can be developed to directly observe the intermediate states and adsorption sites during the reaction process.

(2) Electrocatalytic $\mathrm{CO}_{2} \mathrm{RRs}$ involve complex proton/electron transfer processes, that occur at different time scales. The use of a combination of suitable time-resolved spectroscopies, such as time-resolved fluorescence spectroscopy, transient absorption spectroscopy, and transient photovoltage spectroscopy, is expected to offer insights into the electron transfer processes between different surface interfaces and components.

(3) Classic POMs tend to show good stability in acidic environments, while their stability is poor at higher $\mathrm{pH}$ values. Given their adjustable negative charges and abundant surface reaction sites, POM immobilization and encapsulation can be achieved through host-guest chemistry, coordination polymers or organic functional group modification to promote their electrochemical stability. Moreover, considering the rich elemental composition of the POM family, POMs containing Nb, Pd, and Ti can be developed for electrocatalytic $\mathrm{CO}_{2} \mathrm{RRs}$, and used as a nanocluster models for the investigation of the active components in electrocatalytic $\mathrm{CO}_{2} \mathrm{RRs}$ and broadening the stability of POMs to neutral or even alkaline conditions.

In summary, although our understanding of the critical role of POMs in electrocatalytic $\mathrm{CO}_{2}$ reduction is still limited, there remains great potential for developing promising POM-based electrocatalysts. By exploiting the model role of POM-based electrocatalysts in electrocatalytic $\mathrm{CO}_{2} \mathrm{RRs}$ to develop a deeper understanding of the activation, adsorption, and electron transfer processes during $\mathrm{CO}_{2} \mathrm{RR}$, it should be possible to control the product selectivity and reduction depth of $\mathrm{CO}_{2} \mathrm{RRs}$ in order to convert $\mathrm{CO}_{2}$ into the energy and chemicals on which humanity depends.

\section{Author contributions}

J. Du, H. Q. Tan, Z. H. Kang and Y. G. Li conceived the idea. J. Du. and Y. Y. Ma surveyed and summarized the literatures. All the authors discussed and wrote the manuscript.

\section{References}

[1] J. Fu, K. Jiang, X. Qiu, J. Yu, M. Liu, Mater. Today, 2020, 32, 222-243.

[2] Z. J. Wang, H. Song, H. Liu, J. Ye, Angew. Chem. Int. Ed., 2020, 59, 8016-8035.

[3] L. Liu, L. Zhou, B. Vaughn, J. B. Miller, W. A. Brand, M. Rothe, L. Xia, J. Geophys. Res.-Atmos., 2014, 119, 5602-5612.

[4] D. Li, M. Kassymova, X. Cai, S.-Q. Zang, H.-L. Jiang, Coord. Chem. Rev., 2020, 412, 213262-213277.

[5] R. S. Nowak, S. F. Zitzer, D. Babcock, V. Smith-Longozo, T. N. Charlet, J. S. Coleman, J. R. Seemann, S. D. Smith, Ecology, 2004, 85, 
93-99.

[6] L. Cao, K. Caldeira, Geophys. Res. Lett., 2008, 35, L19609.

[7] X. Duan, J. Xu, Z. Wei, J. Ma, S. Guo, S. Wang, H. Liu, S. Dou, Adv. Mater., 2017, 29, 1701784.

[8] Z. Sun, T. Ma, H. Tao, Q. Fan, B. Han, Chem, 2017, 3, 560-587.

[9] N. S. Spinner, J. A. Vega, W. E. Mustain, Catal. Sci. Technol., 2012, 2, 19-28.

[10] C. Song, Catal. Today, 2006, 115, 2-32.

[11] A. Mustafa, B. G. Lougou, Y. Shuai, Z. Wang, H. Tan, J. Energy Chem., 2020, 49, 96-123.

[12] M. C. J. Bradford, M. A. Vannice, E. Ruckenstein, Catal. Rev. Sci. Eng., 1999, 41, 1-42.

[13] T.-L. Chen, W. Jiang, A.-L. Shen, Y.-H. Chen, S.-Y. Pan, P.-C. Chiang, Ind. Eng. Chem. Res., 2020, 59, 7140-7150.

[14] A. M. Appel, J. E. Bercaw, A. B. Bocarsly, H. Dobbek, D. L. DuBois, M. Dupuis, J. G. Ferry, E. Fujita, R. Hille, P. J. Kenis, C. A. Kerfeld, R. H. Morris, C. H. Peden, A. R. Portis, S. W. Ragsdale, T. B. Rauchfuss, J. N. Reek, L. C. Seefeldt, R. K. Thauer, G. L. Waldrop, Chem. Rev., 2013, 113, 6621-6658.

[15] Y. Xia, Z. Tian, T. Heil, A. Meng, B. Cheng, S. Cao, J. Yu, M. Antonietti, Joule, 2019, 3, 2792-2805.

[16] A. J. Carrillo, A. H. Bork, T. Moser, E. Sediva, Z. D. Hood, J. L. M. Rupp, Adv. Energy Mater., 2019, 9, 1803886.

[17] J. Huang, M. Mensi, E. Oveisi, V. Mantella, R. Buonsanti, J. Am. Chem. Soc., 2019, 141, 2490-2499.

[18] Z. Yin, G. T. R. Palmore, S. Sun, Trends Chem., 2019, 1, 739-750.

[19] N. Han, P. Ding, L. He, Y. Li, Y. Li, Adv. Energy Mater., 2019, 10, 1902338.

[20] D. Salvatore, C. P. Berlinguette, ACS Energy Lett., 2019, 5, 215-220.

[21] W. Zhang, C. Huang, Q. Xiao, L. Yu, L. Shuai, P. An, J. Zhang, M. Qiu, Z. Ren, Y. Yu, J. Am. Chem. Soc., 2020, 142, 11417-11427.

[22] X. Zhao, L. Du, B. You, Y. Sun, Catal. Sci. Technol., 2020, 10, 2711-2720.

[23] S. Liang, N. Altaf, L. Huang, Y. Gao, Q. Wang, J. $\mathrm{CO}_{2}$ Util., 2020, 35, 90-105.

[24] F.-Y. Gao, R.-C. Bao, M.-R. Gao, S.-H. Yu, J. Mater. Chem. A, 2020, 8, 15458-15478.

[25] J. Resasco, A. T. Bell, Trends Chem., 2020, 2, 825-836.

[26] O. G. Sánchez, Y. Y. Birdja, M. Bulut, J. Vaes, T. Breugelmans, D. Pant, Curr. Opin. Green Sust., 2019, 16(s1), 47-56.

[27] M. Bourrez, F. Molton, S. Chardon-Noblat, A. Deronzier, Angew. Chem. Int. Ed., 2011, 50, 9903-9906.

[28] A. Sinopoli, N. T. La Porte, J. F. Martinez, M. R. Wasielewski, M.
Sohail, Coord. Chem. Rev., 2018, 365, 60-74.

[29] M. Stanbury, J.-D. Compain, S. Chardon-Noblat, Coord. Chem. Rev., 2018, 361, 120-137.

[30] J. Schneider, H. Jia, K. Kobiro, D. E. Cabelli, J. T. Muckerman, E. Fujita, Energy Environ. Sci., 2012, 5, 9502-9510.

[31] M. Isaacs, J. C. Canales, M. J. Aguirre, G. Estiú, F. Caruso, G. Ferraudi, J. Costamagna, Inorg. Chim. Acta, 2002, 339, 224-232.

[32] J. Costamagna, G. Ferraudi, J. Canales, J. Vargas, Coord. Chem. Rev., 1996, 148, 221-248.

[33] M. Rudolph, S. Dautz, E.-G. Jäger, J. Am. Chem. Soc., 2000, 122, 10821-10830.

[34] H. Liu, J. Chu, Z. Yin, X. Cai, L. Zhuang, H. Deng, Chem, 2018, 4 , 1696-1709.

[35] S. Lin, C. S. Diercks, Y. B. Zhang, N. Kornienko, E. M. Nichols, Y. Zhao, A. R. Paris, D. Kim, P. Yang, O. M. Yaghi, C. J. Chang, Science, 2015, 349, 1208-1213.

[36] P. L. Cheung, S. K. Lee, C. P. Kubiak, Chem. Mater., 2019, 31, 1908-1919.

[37] Y. R. Wang, Q. Huang, C. T. He, Y. Chen, J. Liu, F. C. Shen, Y. Q. Lan, Nat. Commun., 2018, 9, 4466.

[38] I. Hod, M. D. Sampson, P. Deria, C. P. Kubiak, O. K. Farha, J. T. Hupp, ACS Catal., 2015, 5, 6302-6309.

[39] F. N. Al-Rowaili, A. Jamal, M. S. Ba Shammakh, A. Rana, ACS Sustain. Chem. Eng., 2018, 6, 15895-15914.

[40] E. Zhang, T. Wang, K. Yu, J. Liu, W. Chen, A. Li, H. Rong, R. Lin, S. Ji, X. Zheng, Y. Wang, L. Zheng, C. Chen, D. Wang, J. Zhang, Y. Li, J. Am. Chem. Soc., 2019, 141, 16569-16573.

[41] Y. N. Gong, L. Jiao, Y. Qian, C. Y. Pan, L. Zheng, X. Cai, B. Liu, S. H. Yu, H. L. Jiang, Angew. Chem. Int. Ed., 2020, 59, 2705-2709.

[42] X. Su, X. F. Yang, Y. Huang, B. Liu, T. Zhang, Acc Chem. Res., 2019, $52,656-664$.

[43] S. Sen, D. Liu, G. T. R. Palmore, ACS Catal., 2014, 4, 3091-3095.

[44] D. Gao, H. Zhou, F. Cai, J. Wang, G. Wang, X. Bao, ACS Catal., 2018, 8, 1510-1519.

[45] Y. Hori, K. Kikuchi, A. Murata, S. Suzuki, Chem. Lett., 1986, 897-898.

[46] J. He, N. J. J. Johnson, A. Huang, C. P. Berlinguette, ChemSusChem, 2018, 11, 48-57.

[47] J. Shao, Y. Wang, D. Gao, K. Ye, Q. Wang, G. Wang, Chin. J. Catal., 2020, 41, 1393-1400.

[48] Y. Wang, L. Cao, N. J. Libretto, X. Li, C. Li, Y. Wan, C. He, J. Lee, J. Gregg, H. Zong, D. Su, J. T. Miller, T. Mueller, C. Wang, J. Am. Chem. Soc., 2019, 141, 16635-16642.

\section{Graphical Abstract}

Chin. J. Catal., 2021, 42: 920-937 doi: 10.1016/S1872-2067(20)63718-4

Progress of electrochemical $\mathrm{CO}_{2}$ reduction reactions over polyoxometalate-based materials

Jing Du, Yuan-Yuan Ma, Huaqiao Tan *, Zhen-Hui Kang *,

Yangguang $\mathrm{Li}^{*}$

Northeast Normal University; Soochow University;

Hebei Normal University

Recent progress in the field of electrochemical $\mathrm{CO}_{2}$ reduction reactions over polyoxometalate (POM)-based materials have been summarized and critically reviewed, highlighting the activity origin and reaction mechanisms of POM-based materials.

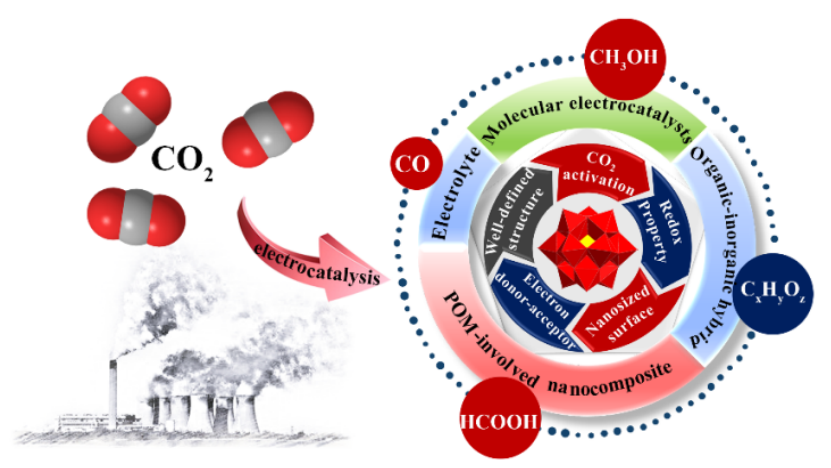


[49] K. Zhao, Y. Liu, X. Quan, S. Chen, H. Yu, ACS Appl. Mater. Interfaces, 2017, 9, 5302-5311.

[50] L. Liu, N. Tian, L. Huang, Y.-H. Hong, A.-Y. Xie, F.-Y. Zhang, C. Xiao, Z.-Y. Zhou, S.-G. Sun, Chin. J. Catal., 2016, 37, 1070-1075.

[51] J. Xu, X. Li, W. Liu, Y. Sun, Z. Ju, T. Yao, C. Wang, H. Ju, J. Zhu, S. Wei, Y. Xie, Angew. Chem. Int. Ed., 2017, 56, 9121-9125.

[52] S. Siahrostami, K. Jiang, M. Karamad, K. Chan, H. Wang, J. Nørskov, ACS Sustain. Chem. Eng., 2017, 5, 11080-11085.

[53] X. Liu, L. Dai, Nat. Rev. Mater., 2016, 1, 16064.

[54] I. V. Kozhevnikov, Chem. Rev., 1998, 98, 171-198.

[55] S. An, J.-C. Liu, H. Zhang, L. Wu, B. Qi, Y.-F. Song, Sci. China Chem., 2019, 62, 159-161.

[56] K. V. Avramidou, F. Zaccheria, S. A. Karakoulia, K. S. Triantafyllidis, N. Ravasio, Mol. Catal., 2017, 439, 60-71.

[57] J. T. Rhule, C. L. Hill, D. A. Judd, R. F. Schinazi, Chem. Rev., 1998, 98, 327-358.

[58] T. Yamase, Chem. Rev., 1998, 98, 307-326.

[59] L. Chen, W. L. Chen, X. L. Wang, Y. G. Li, Z. M. Su, E. B. Wang, Chem. Soc. Rev., 2019, 48, 260-284.

[60] J. Paul, P. Page, P. Sauers, K. Ertel, C. Pasternak, W. Lin, M. Kozik, in: T. Yamase, M. T. Pope, eds., Polyoxometalate Chemistry for Nano-Composite Design, Springer US, Boston, MA, 2002, 205-215.

[61] W. H. Fang, L. Zhang, J. Zhang, J. Am. Chem. Soc., 2016, 138, 7480-7483.

[62] Z. Huang, W. Luo, L. Ma, M. Yu, X. Ren, M. He, S. Polen, K. Click, B. Garrett, J. Lu, K. Amine, C. Hadad, W. Chen, A. Asthagiri, Y. Wu, Angew. Chem. Int. Ed., 2015, 54, 15181-15185.

[63] M. N. Sokolov, I. V. Kalinina, E. V. Peresypkina, E. Cadot, S. V. Tkachev, V. P. Fedin, Angew. Chem. Int. Ed., 2008, 47, 1465-1468.

[64] J. Kang, B. Xu, Z. Peng, X. Zhu, Y. Wei, D. R. Powell, Angew. Chem. Int. Ed., 2005, 117, 7062-7065.

[65] L. Vilà-Nadal, L. Cronin, Nat. Rev. Mater., 2017, 2, 17054.

[66] M. Sadakane, E. Steckhan, Chem. Rev., 1998, 98, 219-238.

[67] M.-Y. Wang, R. Ma, L.-N. He, Sci. China Chem., 2016, 59, 507-516.

[68] B. Yu, B. Zou, C.-W. Hu, J. CO ${ }_{2}$ Util., 2018, 26, 314-322.

[69] Y. Cao, Q. Chen, C. Shen, L. He, Molecules, 2019, 24, 2069.

[70] Y. Zhang, J. Liu, S.-L. Li, Z.-M. Su, Y.-Q. Lan, Energy Chem, 2019, 1, 100021.

[71] J. Schneider, H. Jia, J.T. Muckerman, E. Fujita, Chem. Soc. Rev., 2012, 41, 2036-2051.

[72] Y. Hori, H. Wakebe, T. Tsukamoto, O. Koga, Electrochim. Acta, 1994, 39, 183-1839.

[73] R. Kortlever, J. Shen, K. J. Schouten, F. Calle-Vallejo, M. T. Koper, J. Phys. Chem. Lett., 2015, 6, 4073-4082.

[74] J.-P. Jones, G. K. S. Prakash, G. A. Olah, Israel J. Chem., 2014, 54, 1451-1466.

[75] H. A. Hansen, J. B. Varley, A. A. Peterson, J. K. Norskov, J. Phys. Chem. Lett., 2013, 4, 388-392.

[76] D. C. Lacy, C. C. L. McCrory, J. C. Peters, Inorg. Chem., 2014, 53, 4980-4988.

[77] X. Cui, J. Wang, B. Liu, S. Ling, R. Long, Y. Xiong, J. Am. Chem. Soc., 2018, 140, 16514-16520.

[78] L. D. Chen, M. Urushihara, K. Chan, J. K. Nørskov, ACS Catal., 2016, 6, 7133-7139.

[79] M. L. Clark, A. Ge, P. E. Videla, B. Rudshteyn, C. J. Miller, J. Song, V. S. Batista, T. Lian, C. P. Kubiak, J. Am. Chem. Soc., 2018, 140, 17643-17655.

[80] Y. Yang, L. Ohnoutek, S. Ajmal, X. Zheng, Y. Feng, K. Li, T. Wang, Y. Deng, Y. Liu, D. Xu, V. K. Valev, L. Zhang, J. Mater. Chem. A, 2019, 7, 11836-11846.

[81] Y. Wang, P. Han, X. Lv, L. Zhang, G. Zheng, Joule, 2018, 2,
2551-2582.

[82] D. Kim, J. Resasco, Y. Yu, A. M. Asiri, P. Yang, Nat. Commun., 2014, $5,4948$.

[83] A. Eilert, F. Cavalca, F. S. Roberts, J. Osterwalder, C. Liu, M. Favaro, E. J. Crumlin, H. Ogasawara, D. Friebel, L. G. Pettersson, A. Nilsson, J. Phys. Chem. Lett., 2017, 8, 285-290.

[84] K. Chan, C. Tsai, H. A. Hansen, J. K. Nørskov, ChemCatChem, 2014, 6, 1899-1905.

[85] A. S. Varela, M. Kroschel, T. Reier, P. Strasser, Catal. Today, 2016, 260, 8-13.

[86] D. M. Weekes, D. A. Salvatore, A. Reyes, A. Huang, C. P. Berlinguette, Acc. Chem. Res., 2018, 51, 910-918.

[87] D. Gao, H. Zhou, F. Cai, D. Wang, Y. Hu, B. Jiang, W.-B. Cai, X. Chen, R. Si, F. Yang, S. Miao, J. Wang, G. Wang, X. Bao, Nano Res., 2017, 10, 2181-2191.

[88] S. H. Szczepankiewicz, C. M. Ippolito, B. P. Santora, T. J. Van De Ven, G. A. Ippolito, L. Fronckowiak, F. Wiatrowski, T. Power, M. Kozik, Inorg. Chem., 1998, 37, 4344-4352.

[89] G. Gao, F. Li, L. Xu, X. Liu, Y. Yang, J. Am. Chem. Soc., 2008, 130, 10838-10839.

[90] D. L. Long, R. Tsunashima, L. Cronin, Angew. Chem. Int. Ed., 2010 , 49, 1736-1758.

[91] K. Watenpaugh, C. N. Caughlan, Chem. Comm., 1967, 76-77.

[92] Y. Lv, J. Cheng, A. Steiner, L. Gan, D. S. Wright, Angew. Chem. Int. Ed., 2014, 53, 1934-1938.

[93] P. Yang, U. Kortz, Acc. Chem. Res., 2018, 51, 1599-1608.

[94] N. I. Gumerova, A. Rompel, Nat. Rev. Chem., 2018, 2, 0112.

[95] L. MacDonald, J. C. McGlynn, N. Irvine, I. Alshibane, L. G. Bloor, B. Rausch, J. S. J. Hargreaves, L. Cronin, Sustain. Energy Fuels, 2017, 1, 1782-1787.

[96] B. Rausch, M. D. Symes, G. Chisholm, L. Cronin, Science, 2014, 345, 1326-1330.

[97] M. Girardi, S. Blanchard, S. Griveau, P. Simon, M. Fontecave, F. Bedioui, A. Proust, Eur. J. Inorg. Chem., 2015, 2015, 3642-3648.

[98] M. Girardi, D. Platzer, S. Griveau, F. Bedioui, S. Alves, A. Proust, S. Blanchard, Eur. J. Inorg. Chem., 2019, 2019, 387-393.

[99] J.-X. Liu, X.-B. Zhang, Y.-L. Li, S.-L. Huang, G.-Y. Yang, Coord. Chem. Rev., 2020, 414, 213260.

[100] M. García, M. J. Aguirre, G. Canzi, C. P. Kubiak, M. Ohlbaum, M. Isaacs, Electrochim. Acta, 2014, 115, 146-154.

[101]J. Du, Z.-L. Lang, Y.-Y. Ma, H.-Q. Tan, B.-L. Liu, Y.-H. Wang, Z.-H. Kang, Y.-G. Li, Chem. Sci., 2020, 11, 3007-3015.

[102] S. X. Guo, D. R. MacFarlane, J. Zhang, ChemSusChem, 2016, 9, 80-87.

[103] B. Zha, C. Li, J. Li, J. Catal., 2020, 382, 69-76.

[104] C. Li, B. Zha, J. Li, J. CO ${ }_{2}$ Util., 2020, 38, 299-305.

[105] S. X. Guo, F. Li, L. Chen, D. R. MacFarlane, J. Zhang, ACS Appl. Mater. Interfaces, 2018, 10, 12690-12697.

[106]S. X. Guo, Y. Zhang, X. Zhang, C. D. Easton, D. R. MacFarlane, J. Zhang, ChemSusChem, 2019, 12, 1091-1100.

[107] H. E. Toma, K. Araki, Coord. Chem. Rev., 2000, 196, 307-329.

[108] N. Han, Y. Wang, L. Ma, J. Wen, J. Li, H. Zheng, K. Nie, X. Wang, F. Zhao, Y. Li, J. Fan, J. Zhong, T. Wu, D. J. Miller, J. Lu, S.-T. Lee, Y. Li, Chem, 2017, 3, 652-664.

[109] M. Bourrez, F. Molton, S. Chardon-Noblat, A. Deronzier, Angew. Chem. Int. Ed., 2011, 50, 9903-9906.

[110] K. Lv, Y. Fan, Y. Zhu, Y. Yuan, J. Wang, Y. Zhu, Q. Zhang, J. Mater. Chem. A, 2018, 6, 5025-5031.

[111] M. Liu, M. Liu, X. Wang, S. M. Kozlov, Z. Cao, P. De Luna, H. Li, X. Qiu, K. Liu, J. Hu, C. Jia, P. Wang, H. Zhou, J. He, M. Zhong, X. Lan, Y. Zhou, Z. Wang, J. Li, A. Seifitokaldani, C. T. Dinh, H. Liang, C. Zou, D. Zhang, Y. Yang, T.-S. Chan, Y. Han, L. Cavallo, T.-K. Sham, B.-J. 
Hwang, E. H. Sargent, Joule, 2019, 3, 1703-1718.

[112]Z. Zhang, F. Ahmad, W. Zhao, W. Yan, W. Zhang, H. Huang, C. Ma, J. Zeng, Nano Lett., 2019, 19, 4029-4034.

[113]W. Ma, S. Xie, X.-G. Zhang, F. Sun, J. Kang, Z. Jiang, Q. Zhang, D.-Y. Wu, Y. Wang, Nat. Commun., 2019, 10, 892.

[114]S. Kim, W. J. Dong, S. Gim, W. Sohn, J. Y. Park, C. J. Yoo, H. W. Jang, J.-L. Lee, Nano Energy, 2017, 39, 44-52.

[115]D. Wang, L. L. Liu, J. Jiang, L. J. Chen, J. W. Zhao, Nanoscale, 2020, $12,5705-5718$.

[116]N. Li, J. Liu, B.-X. Dong, Y.-Q. Lan. Angew. Chem. Int. Ed., 2020, doi:10.1002/anie.202008054

[117] A. S. Cherevan, S. P. Nandan, I. Roger, R. Liu, C. Streb, D. Eder, Adv. Sci., 2020, 7, 1903511.

[118] X.-B. Han, D.-X. Wang, E. Gracia-Espino, Y.-H. Luo, Y.-Z. Tan, D.-F. Lu, Y.-G. Li, T. Wågberg, E.-B. Wang, L.-S. Zheng, Chin. J. Catal., 2020, 41, 853-857.

[119] D. X. Liu, B. Wang, H. G. Li, S. F. Huang, M. M. Liu, J. Wang, Q. J. Wang, J. J. Zhang, Y. F. Zhao, Nano Energy, 2019, 58, 277-283.

[120] J. Zhang, Q. A. Huang, J. Wang, J. Wang, J. J. Zhang, Y. F. Zhao, Chin. J. Catal., 2020, 41, 783-798.

\title{
多金属氧酸盐材料在二氧化碳电催化还原领域中的研究进展
}

\author{
都 京 ${ }^{\mathrm{a}, \dagger}$, 马媛媛 ${ }^{\mathrm{d}, \dagger}$, 谭华桥 ${ }^{\mathrm{a}, *}$, 康振辉, $\mathrm{b}$, , , 李阳光 ${ }^{\mathrm{a}, \$}$ \\ a东北师范大学化学学院, 多酸科学教育部重点实验室, 吉林长春 130024 \\ ${ }^{\mathrm{b}}$ 东北师范大学先进材料研究院, 吉林长春 130024 \\ '苏州大学功能纳米与软物质研究院, 江苏省碳基功能材料与器件重点实验室, 江苏苏州 215213

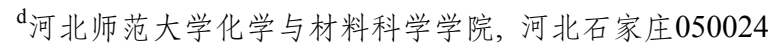

摘要: 随着工业发展和全球人口的持续增长, 人类对化石燃料的消耗日益增加, 从而导致大气中二氧化碳含量的显著增加 以及与之相伴的一系列环境问题. 电化学还原二氧化碳制备高附加值的燃料和化学品具有稳定的效率和较高的经济可行 性等特点, 目前已成为一种有前景的策略来缓解当前全球面临的能源短缺和气候变暖问题. 然而, 电催化二氧化碳还原过 程存在反应能垒高和复杂的多电子/质子耦合过程等不足, 因此, 合理有效的电催化剂设计成为该领域的关键问题. 近年, 理解和明确电化学二氧化碳还原反应过程的活性起源、选择性调控机制和催化反应机理已成为高效电催化剂设计过程中 的重要指导原则. 作为一类独特的纳米尺度的金属氧簇, 多金属氧酸盐(多酸)已成为二氧化碳还原领域的热点材料. 尤其 是, 多酸明确的结构、优越的电子/质子存储转移能力和二氧化碳吸附活化能力有助于探究二氧化碳还原反应过程中的活 性起源和构效机制. 因此, 利用多酸阐明电化学二氧化碳还原反应中的这些关键问题对于开发高效、可实用化的电催化剂 意义重大.

本文综述了近年多酸在电催化二氧化碳还原反应中取得的进展, 重点介绍了多酸阴离子均相分子催化剂、多酸基无机 -有机杂化材料催化剂、多酸电解质溶液、多酸-纳米复合材料在电催化二氧化碳还原反应中的应用. 利用密度泛函理论结 合原位实验证据推测了可能的反应机理, 探讨了多酸对电催化活性和产物选择性的影响, 揭示了电子/质子存储-转移过程 和多酸表面修饰工程在电催化二氧化碳还原过程中的重要作用. 最后, 本文还分析了多酸基材料存在的问题与面临的挑 战, 并对多酸基材料在二氧化碳还原领域的未来发展进行了展望, 这对理解电催化二氧化碳还原反应中的关键步骤和开发 新型高效的电催化二氧化碳还原电催化剂具有启发意义.

关键词: 多金属氧酸盐; 电催化; 二氧化碳还原; 电子转移; 机理

收稿日期: 2020-07-22. 接受日期: 2020-09-03. 上网日期: 2020-11-22.

*通讯联系人. 电子信箱: tanhq870@nenu.edu.cn

\#通讯联系人. 电子信箱: kangzh@nenu.edu.cn; zhkang@suda.edu.cn

通讯联系人. 电子信箱: liyg658@nenu.edu.cn

†共同第一作者.

基金来源：国家自然科学基金(21671036, 21771033，21771132，21901060，51725204，51972216，52041202); 中央高校基础研究基 金项目(2412018BJ001，2412018ZD007，2412018QD005)，国家MCF能源研究与开发计划(2018YFE0306105); 国家自然科学基金 创新研究群体项目 (51821002); 江苏省自然科学基金(BK20190041, BK20190828); 广东省重点领域研发计划项目 (2019B010933001); 苏州纳米科技协同创新中心; 江苏省高等学校重点学科建设项目; 111 计划; 吉林省科技发展计划项目 (20190201206JC); 吉林省教育厅基金项目(JJKH20190268KJ); 高等学校博士学科点专项科研基金(20123201110018); 多酸科学 教育部重点实验室开放项目。

本文的电子版全文由Elsevier出版社在ScienceDirect上出版(http://www.sciencedirect.com/science/journal/18722067). 